\title{
Thermal Energy Delivery System Design Basis Report
}

Carl Stoots

Alexander Duenas

Piyush Sabharwall

James O'Brien

Jun Soo Yoo

Shannon Bragg-Sitton

September 2018

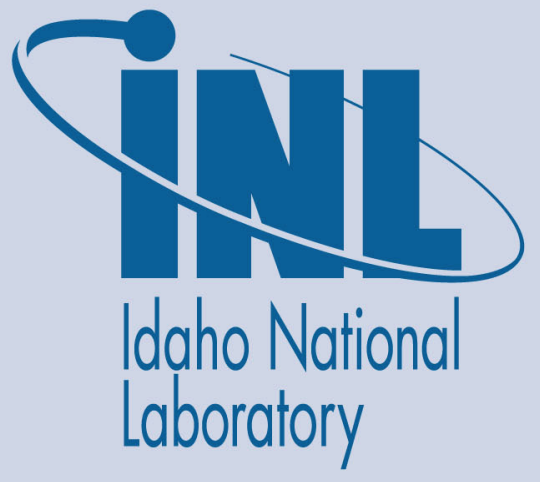

The INL is a U.S. Department of Energy National Laboratory operated by Battelle Energy Alliance 


\section{DISCLAIMER}

This information was prepared as an account of work sponsored by an agency of the U.S. Government. Neither the U.S. Government nor any agency thereof, nor any of their employees, makes any warranty, expressed or implied, or assumes any legal liability or responsibility for the accuracy, completeness, or usefulness, of any information, apparatus, product, or process disclosed, or represents that its use would not infringe privately owned rights. References herein to any specific commercial product, process, or service by trade name, trade mark, manufacturer, or otherwise, does not necessarily constitute or imply its endorsement, recommendation, or favoring by the U.S. Government or any agency thereof. The views and opinions of authors expressed herein do not necessarily state or reflect those of the U.S. Government or any agency thereof. 
INL/EXT-18-51351

Revision 0

\title{
Thermal Energy Delivery System Design Basis Report
}

\author{
Carl Stoots \\ Alexander Duenas \\ Piyush Sabharwall \\ James O'Brien \\ Jun Soo Yoo \\ Shannon Bragg-Sitton
}

September 2018

Idaho National Laboratory

Idaho Falls, Idaho 83415

http://www.inl.gov

Prepared for the

U.S. Department of Energy

Office of Nuclear Energy

Under DOE Idaho Operations Office

Contract DE-AC07-05ID14517 


\section{Acknowledgement}

The co-authors of this report would like to thank our friend and colleague, Dr. Carl Stoots, for his hard work and dedication to this project and to other key INL activities over many years. His efforts and leadership are truly appreciated. 


\section{CONTENTS}

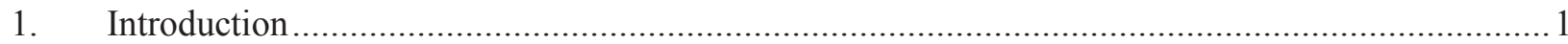

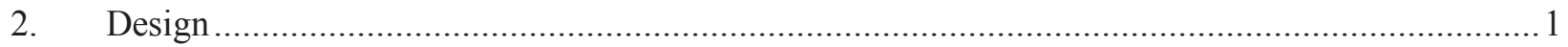

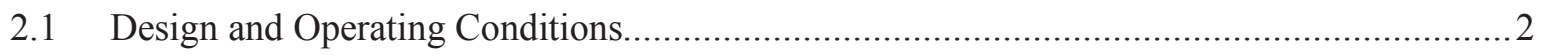

2.2 Piping \& Instrumentation Diagram (P\&ID) .............................................................. 3

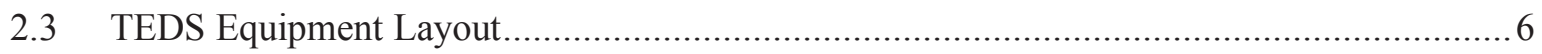

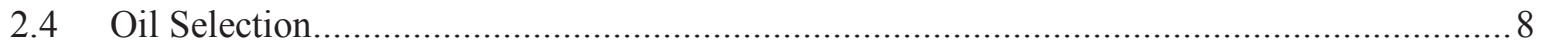

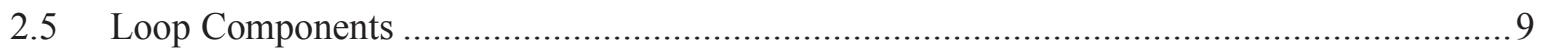

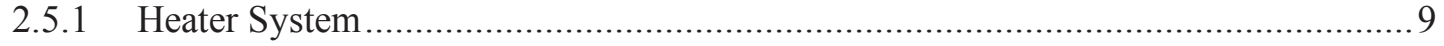

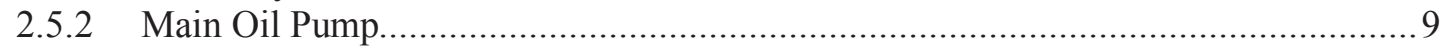

2.5.3 Thermal Energy Storage System................................................................ 9

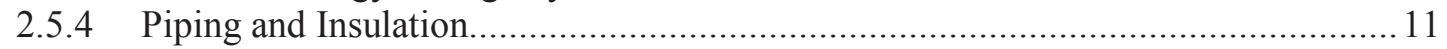

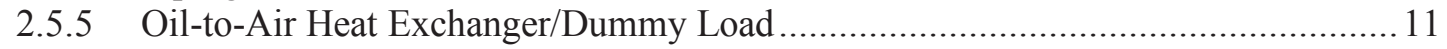

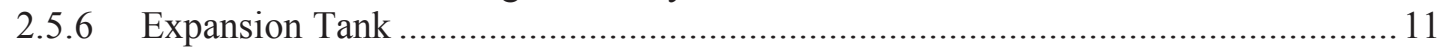

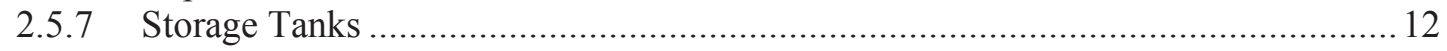

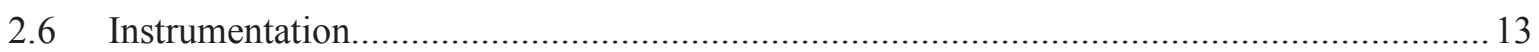

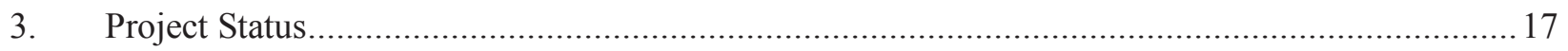

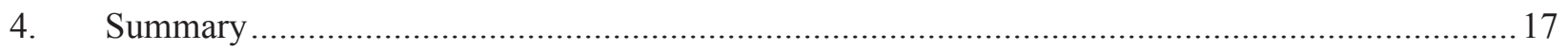

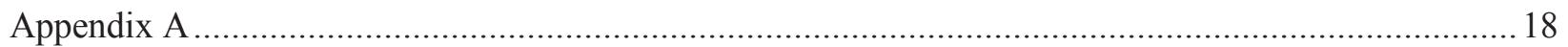

\section{FIGURES}

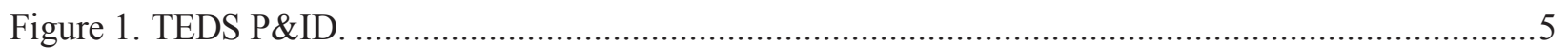

Figure 2. Isometric Views of the TEDS equipment layout. ............................................................ 7

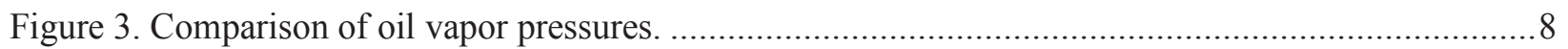

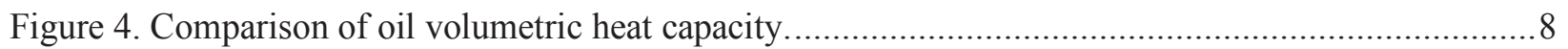

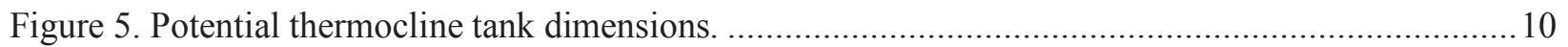

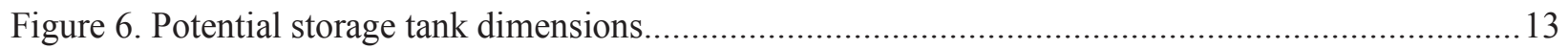

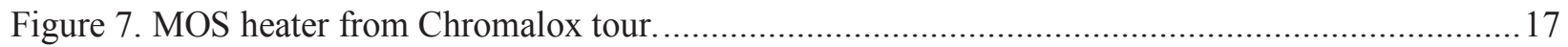

\section{TABLES}

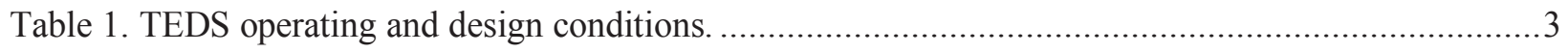

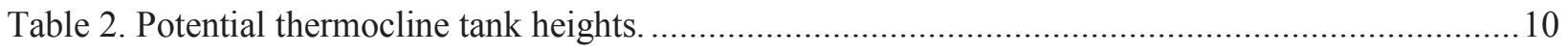

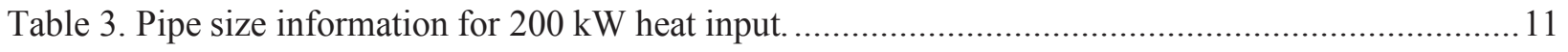

Table 4. Pipe size information for $400 \mathrm{~kW}$ heat input................................................................. 11

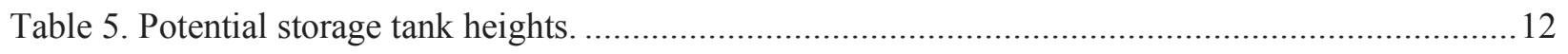

Table 6. Preliminary instrumentation specifications. ............................................................... 15 


\section{Thermal Energy Delivery System Design Basis Report}

\section{Introduction}

Nuclear power plants operate most efficiently and economically when they operate at a constant power output. However, with the current dynamics of the electrical grid, including the introduction and growth of renewable energy sources (such as wind and solar), nuclear generation facilities across the U.S. are finding it difficult to maintain constant power output and provide for baseload generation capacities. As a result, most nuclear plants are finding it hard to compete with other power generation sources, most notably natural gas [1]. Finding a solution to this intermittent demand dynamic could help U.S. nuclear power plants to economically compete with other generation sources, such as natural gas, wind, and solar.

A Dynamic Energy Transport and Integration Laboratory (DETAIL) is being designed for installation within the Energy Systems Laboratory at Idaho National Laboratory (INL) to demonstrate integrated system operation. The overall objective for the DETAIL facility is to demonstrate simultaneous, coordinated, and efficient transient distribution of electricity and heat for power generation, energy storage, and industrial end uses. A dynamically controlled, electrically heated thermal energy production and distribution system has been designed in which heat production from nuclear fuel will be simulated using electrical heating and sophisticated control algorithms to provide simulation of system dynamics within a hardware system. The combined DETAIL facility will provide demonstration of real-time integration with the electrical grid, renewable energy inputs, thermal and electrical energy storage, and energy delivery to an end user. As such, an integrated energy network can be simulated to improve our understanding of how to optimize energy flows while maintaining system stability and efficient operation of all assets in the system.

A Thermal Energy Delivery System (TEDS) is needed within the DETAIL facility to test heat transfer components, distribution systems, instruments, and controls that can be monitored and controlled for hybrid generation of electrical power and/or non-electrical products. As is the case for other subsystems within DETAIL, TEDS is designed to operate as a part of an integrated system or independently to demonstrate the operation of TEDS unit components, to develop and validate thermal energy transport models and control systems, and to study thermal energy inertia and storage. Within the integrated system, TEDS will be connected to the INL Real Time Power Simulation test platform to develop and demonstrate monitoring and control systems and to investigate real-time, hardware-in-theloop response characteristics relative to grid operations. The system can be used to characterize thermal energy inertia and thermal energy management relative to the interoperability of a nuclear plant, power generation, and industrial heat applications. TEDS operation will additionally provide data to validate computational models such as RELAP, Modelica, and other transient physics-based models that can be used to support scale-up of hybrid energy systems for demonstration with operating (fueled) nuclear plants. TEDS can also be used to support cyber-informed engineering of controls and hardware systems.

This report and the corresponding Functional and Operational Requirements (F\&OR, included as Appendix A) document the current TEDS design. Before the design is finalized and sent out for procurement, a design review will be conducted with both internal and external stakeholders to ensure that all intended operational capabilities can be met via the current design.

\section{Design}

TEDS is designed to allow for modulation of the flow rate and temperature of the heat transfer medium and will be capable of diverting thermal energy as required by multiple heat customers. The heat transfer medium selected for use in TEDS is a high-performance, highly stable synthetic heat transfer oil (Therminol 66). A schematic of the TEDS loop is provided in Figure 1. The TEDS facility will be located within the Energy Systems Laboratory (ESL) in the D100 northwest high bay. 
TEDS is designed to deliver process heat supply to heat consumers/customers and to demonstrate associated transport/transmission characteristics and performance in a flexible and dynamic manner, such that the envisioned operational modes can be tested and performance verified. Data acquired using TEDS will support improved modeling of integrated systems and provide data for validation of computational models. Data acquired will include information on time constants, which will aid in the conduct of parametric studies that enable further design improvements and system operational optimization. This test facility will allow researchers to develop an increased understanding of the cyclic behavior (charging and discharging characteristic) of an integrated energy storage system and the system dynamic behavior with integrated industrial applications. The facility will also provide much-needed feedback for control systems to support DETAIL test/demonstration operations.

The overall Nuclear-Renewable Hybrid Energy Systems (N-R HES) program and the planned experimental demonstrations supported by the program will enhance existing DOE and INL core research capabilities, including design of thermal capacitors that can optimize high-temperature thermal energy utilization, thus assisting research in the nuclear industry and heat transport/delivery systems. DETAIL, and TEDS specifically, will support systems integration, demonstration of flexible operation, dynamic model validation, and technical performance characterization of envisioned operational scenarios. The facility can be further expanded in the future to integrate additional systems (e.g. additional energy users) with minimal disruption to TEDS operation by establishing a control strategy to divert the flow as required (based on various demand conditions, control signals, etc.) and adjust the temperature and flow rate accordingly.

\subsection{Design and Operating Conditions}

TEDS will have design and operating conditions as shown in Table 1. The limiting design pressure of 100 psig was selected to accommodate the pressure ratings of the vendor-acquired components, including the heater system, oil pump, expansion tank, and filtration system. Because Therminol 66 has a low vapor pressure $\left(10.3 \mathrm{psi}\right.$ at $\left.340^{\circ} \mathrm{C}\right)$, the system does not need to be pressurized and does not drive the design pressure selection. Establishing the design pressure as 100 psig allows the components acquired from vendors to be procured without pressure modification, which would have substantially driven up costs. Additionally, this design parameter provides flexibility with pump operation to provide enough total pressure head without concern of over pressurizing the system. The design temperature was selected because the pump, heater, and Therminol 66 are only rated to $343^{\circ} \mathrm{C}$. This design point prevents the system from reaching this temperature, thereby preventing oil, heater, and pump degradation.

The planned operating conditions are lower than the specified design limits to provide operational margin and to allow TEDS to properly interface with other facilities. The $325^{\circ} \mathrm{C}$ maximum operating temperature was selected because it matches the maximum temperature of the pressurized water reactor (PWR) emulation loop, which will interface with the TEDS loop via a heat exchanger. ${ }^{1}$ The nominal flowrate is based on a heat transfer analysis of the required flowrate to heat the oil from 225 to $325^{\circ} \mathrm{C}$ using $200 \mathrm{~kW}$ heat input from either the PWR heat exchanger interface or a supplemental heater system, or a total $400 \mathrm{~kW}$ heat input from both heat sources.

\footnotetext{
${ }^{1}$ J. O’Brien, S-J. Yoon, P. Sabharwall, and S. Bragg-Sitton, High-Pressure High-Temperature Thermal Hydraulic Test Facility for Nuclear-Renewable Hybrid Energy System Studies; Facility Design Description and Status Report, INL/EXT-17-43269, September 2017.
} 
Table 1. TEDS operating and design conditions.

\begin{tabular}{|l|l|}
\hline \multicolumn{1}{|c|}{ Condition } & \multicolumn{1}{c|}{ Value } \\
\hline Design Pressure & $100[\mathrm{psig}]$ \\
\hline Design Temperature & $340\left[{ }^{\circ} \mathrm{C}\right]$ \\
\hline Maximum Oil Operating Temperature & $325\left[{ }^{\circ} \mathrm{C}\right]$ \\
\hline Return Oil Operating Temperature & $225\left[{ }^{\circ} \mathrm{C}\right]$ \\
\hline Maximum Operating Pressure & $14[\mathrm{psig}]$ \\
\hline Nominal flow rate & $0.8-1.62[\mathrm{~kg} / \mathrm{s}](14-33[\mathrm{gpm}])$ \\
\hline Nominal Pipe Size (NPS) & $2[\mathrm{in}]$. \\
\hline
\end{tabular}

\subsection{Piping \& Instrumentation Diagram (P\&ID)}

The TEDS loop process layout is shown in Figure 1. This layout is broken down into four different subsystems. The baseline system is indicated by instruments and valves with the numbering scheme of (type, XXX), the future PWR loop interface is indicated by (1XX) numbering, the thermal energy storage (TES) system is indicated by (2XX) numbering, and the interface with the High Temperature Steam Electrolysis (HTSE) test stand is indicated by (3XX) numbering. Note that the HTSE system is the initial energy user to be demonstrated in DETAIL, but other energy users may be integrated via TEDS in the future.

Looking at Figure 1, the flow path starts from the Mid-Size Hot Oil System (MOS) pump at State Point 1 . The flow can be split and heated at the PWR interface, which will be a heat exchanger, or go directly to the MOS heater system to have its temperature increased from 225 to $325^{\circ} \mathrm{C}$. The valve labeled as GBV-004 is a variable position valve to allow varying flowrates into either piping leg. After the heat transfer fluid (HTF) has been heated to the maximum operating temperature (State Point 2), it can be diverted to the TES system for charging mode (State Point 2a) or to either the HTSE (State Point 4) or oil-to-air heat exchanger (State Point 5) before entering the suction side of the pump. Dashed lines in Figure 1 indicate future components that will be added to the baseline configuration. This includes the PWR interface heat exchanger and the connection to the HTSE. These subsystems will be installed with valved off blind flanges, which will allow flexibility in design of those systems and provide an additional point in the system to drain the HTF.

Valves used in TEDS include check, ball, globe, and gate valves. Globe valves are used in locations to provide variable position control. This will allow variable flowrates into multiple components, which is necessary to meet the loop's function as a distribution system. Check valves are used to prevent flow reversal in critical locations. A check valve is on the discharge side of the pump to prevent flow reversal into the pump, which would cause severe damage. Another check valve is used upstream of the TES discharge outlet piping to prevent flow reversal towards the heater system. The third check valve is used on the expansion tank vent line to prevent air from entering into the expansion tank during venting. The TES tank will have four main valves - GBV-201, GBV-202, GBV-203, and GBV-204 - to support two modes of operation, charging and discharging. The thermal storage system is described in detail in Section 2.5.3. Flow to the oil-to-air heat exchanger and HTSE interface is controlled with ball valves BV008 and BV-009. The piping for BV-009 can act as a bypass line to the oil-to-air heat exchanger to decrease heat-up time when heating the system and when heat removal is not needed.

Pressure in the system is controlled with an expansion tank, which will also be used to vent dissolved gases from components and oil from pressure relief valves in the system. High points in the piping and components will be capable of venting to the storage tank either through the expansion tank or directly to the vent line. The expansion tank is connected to the suction side of the pump to provide net positive suction head. The TES tank's charging outlet piping is connected upstream of the filtration system to 
filter and sample the oil to determine if it is carrying small pieces of the alumina particles from the packed bed.

The instrumentation layout uses thermocouples before and after a component to observe temperature changes, as well as pressure transmitters on the high-temperature side to monitor pressure drop and system conditions. This allows the oil's thermophysical properties to be determined at each component. Flowmeters are preferentially placed on the cold legs of the loop to reduce exposure to the higher system temperatures. Flowmeters were positioned downstream of valves GBV-203 and GBV-204 to provide researchers with accurate flowrate and to allow operators to monitor for leaks from the valves.

Instrumentation shown around the TES tank are used to provide bulk fluid properties and are connected to piping surrounding the tank. More detailed instrumentation of the TES tank is beyond the scope of current work. National Instrument's LabVIEW software will be used to control the flow loop. This software will communicate with the actuators equipped on the valves to control their positions, collect instrumentation data with a data acquisition system, control heater power, adjust pump motor speed with a variable frequency drive (VFD), and have built-in alarms to prevent damage to the flow loop and personnel. 


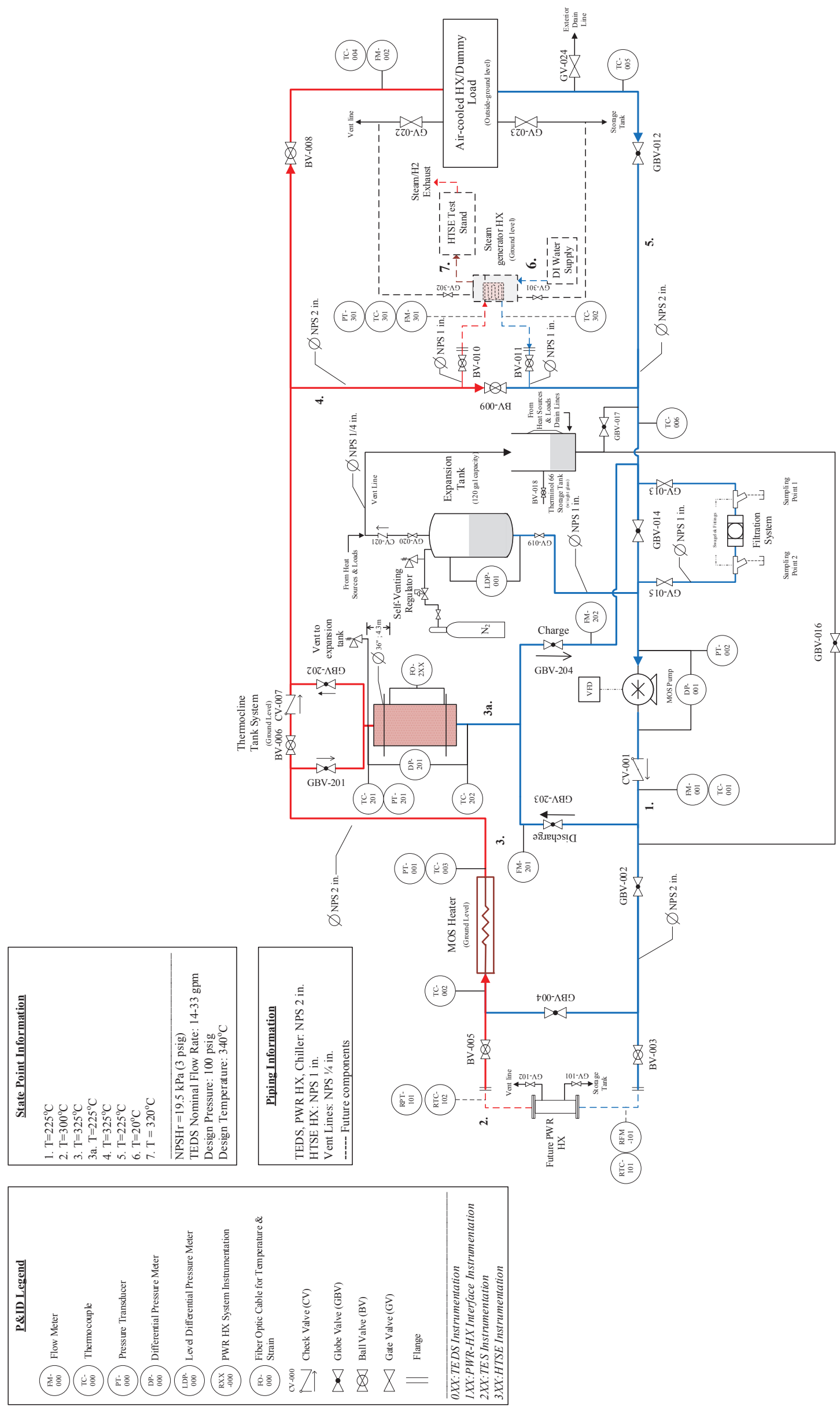




\subsection{TEDS Equipment Layout}

The preliminary equipment layout for TEDS is shown in Figure 2 via two isometric views. This layout uses the 2-inch pipe runs configured per the P\&ID.

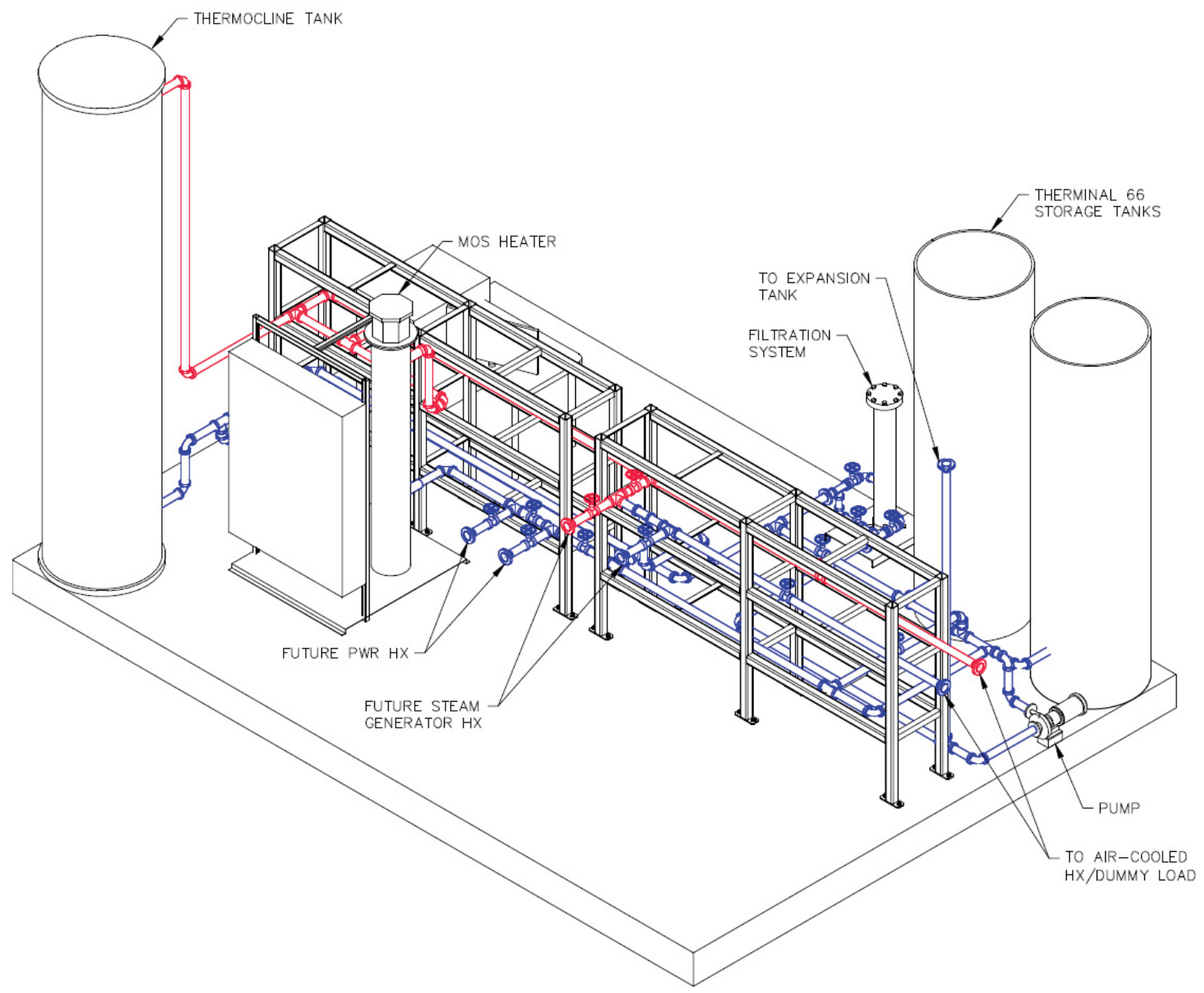

(a) Northwest view. 


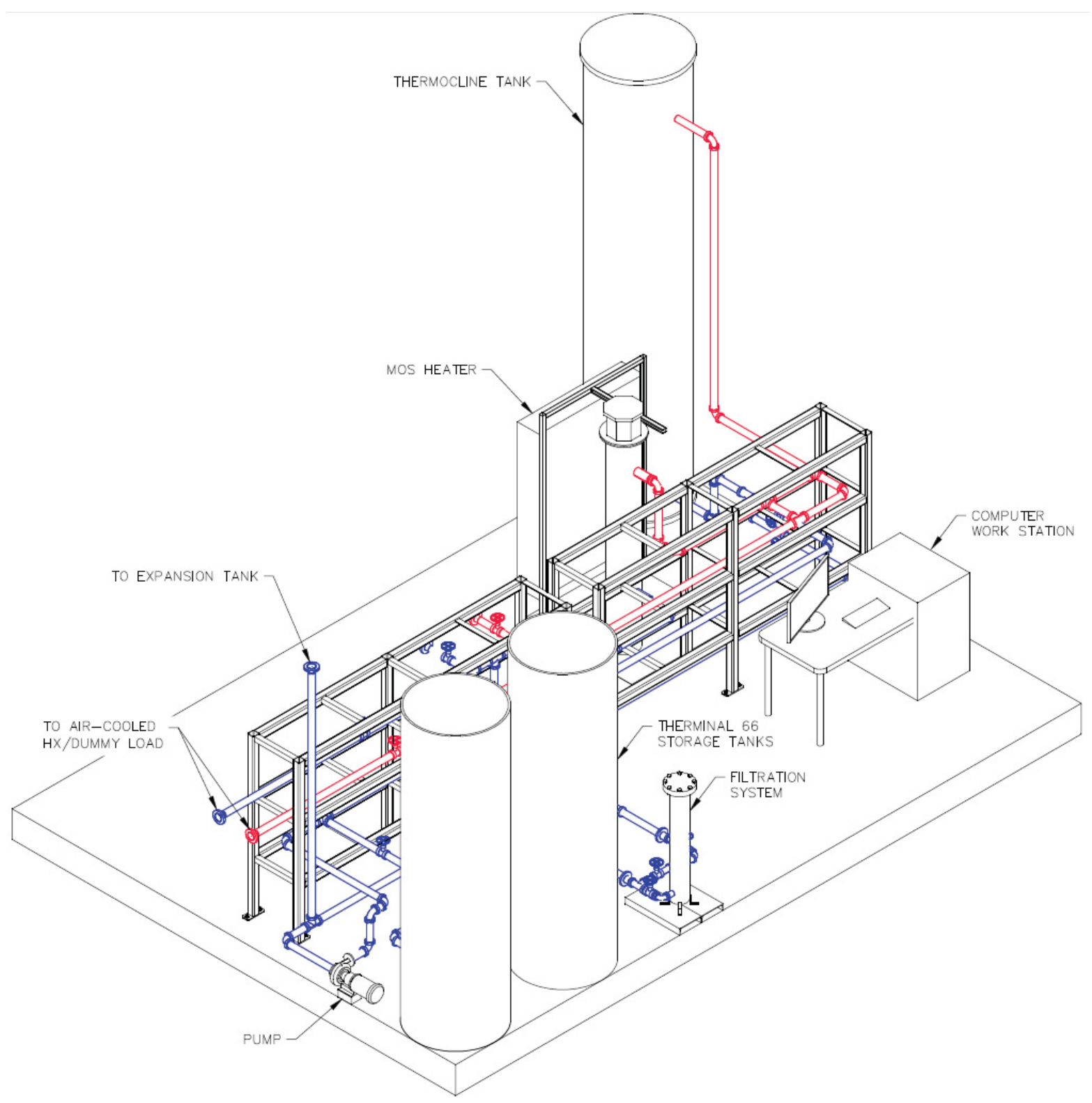

(b) Southwest view.

Figure 2. Isometric Views of the TEDS equipment layout. 


\subsection{Oil Selection}

Therminol 66 was selected as the heat transfer fluid because of its wide operating temperature range $\left(-3\right.$ to $\left.343^{\circ} \mathrm{C}\right)$, low vapor pressure at high temperatures $\left(10.3 \mathrm{psi}\right.$ at $\left.340^{\circ} \mathrm{C}\right)$, and material compatibility. Therminol 66 is a commonly used heat transfer fluid. Figure and Figure show comparisons of vapor pressure and volumetric heat capacity versus temperature for Therminol 66, Therminol VP-1, and Xceltherm. It can be seen that, of these oils, Therminol 66 has the largest volumetric heat capacity and lowest vapor pressure in the operating and design conditions. Parameters such as thermal conductivity and viscosity were comparable between the oils. Other oils, such as Dowtherm A, Dowtherm G, and Drakeol5, were considered, but Therminol 66 had the most preferred properties (vapor pressure, freezing point, boiling point, material compatibility, corrosion, viscosity, etc.) that made it the ideal heat transfer fluid for the TEDS loop.

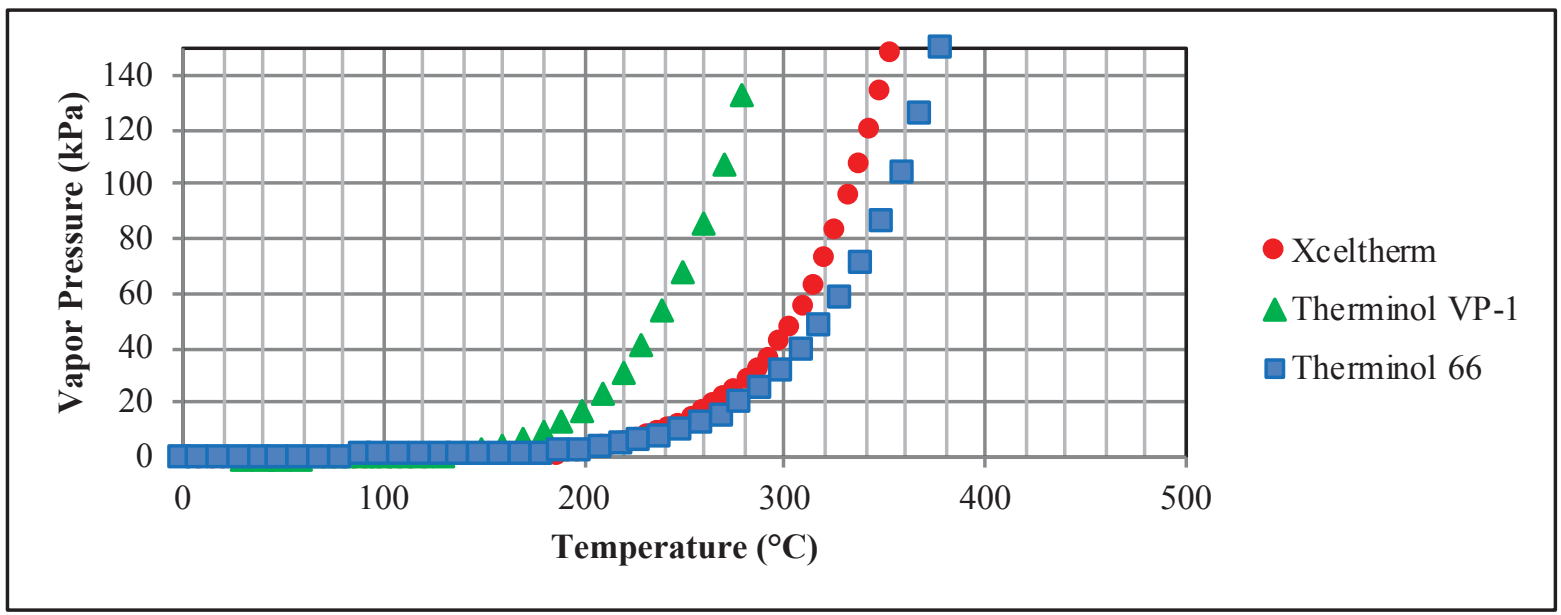

Figure 3. Comparison of oil vapor pressures.

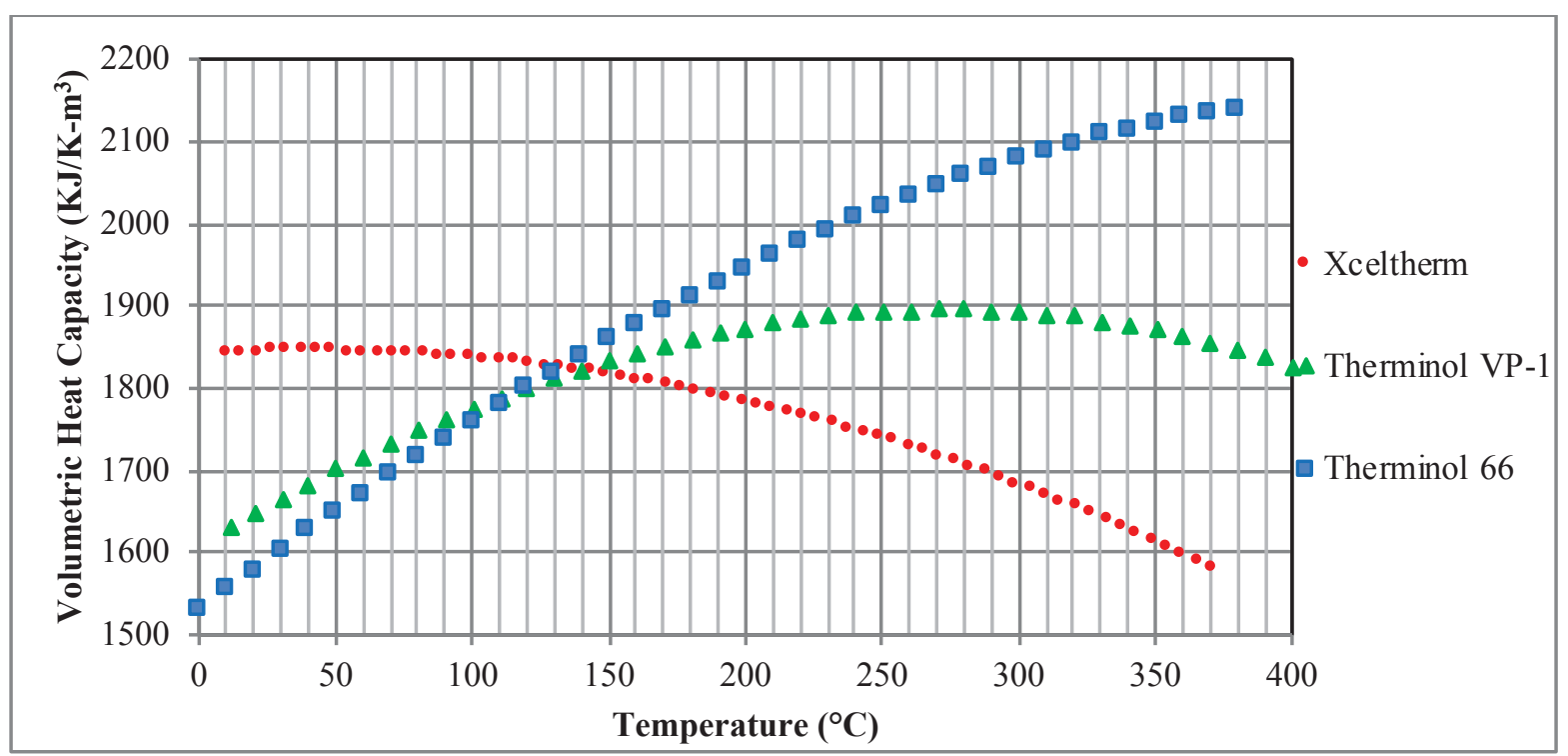

Figure 4. Comparison of oil volumetric heat capacity. 


\subsection{Loop Components}

The TEDS loop consists of a baseline configuration composed of the heater system, oil pump, thermal energy storage system, expansion and storage tanks, and an oil-to-air heat exchanger. Listed below are the requirements and specifications identified for these components, which are based on the design and operating requirements outline in Section 2.1.

\subsubsection{Heater System}

A $200 \mathrm{~kW}$ oil heater system provided by Chromalox has been identified as the oil heater to supplement heat from the PWR heat exchanger interface. This heater system will initially be the heat source for the loop and bring the oil temperature to its maximum $325^{\circ} \mathrm{C}$ operating temperature. The heater is rated up to $343^{\circ} \mathrm{C}\left(650^{\circ} \mathrm{F}\right)$ and will be designed per American Society of Mechanical Engineers (ASME) standards and certified up to the design pressure.

\subsubsection{Main Oil Pump}

A hot oil pump provided by Chromalox will drive flow through the system and supply the necessary nominal flowrate range listed in Table 1 . The oil pump will be capable of meeting the loop design temperature and pressure. The pump will also be used to fill and drain the oil to the storage tanks. The MP Pumps HTO 80 model has been identified for the oil pump because it is rated up to $343^{\circ} \mathrm{C}$ and $150 \mathrm{psig}$, provides flowrates up to $85 \mathrm{gpm}$ and pressure head between 10-60 psi, and has a motor compatible with a variable frequency drive (VFD). This VFD will be used to control the pump's flowrate and will be adjusted with LabVIEW software.

\subsubsection{Thermal Energy Storage System}

The TES system used in TEDS is a single packed bed thermocline tank with 1/8-inch diamter alumina beads as the filler material. The preliminary dimensions range from a 13-14.5-foot height with an outer diameter of 36-inches. The tank will be an ASME designed and certified Section 8 Division 1 vessel. To reduce manufacturing costs and simplify design, the main body of the vessel will be a 36 -inch pipe with an appropriate pipe schedule to meet the loop's design pressure limits. Inside of the tank there will be an upper and lower plenum, which will allow for sufficient mixing of the oil before traveling through the packed pebble bed. These plenums are formed by flow distribution plates located at the top and bottom of the tank. These plates will also prevent the alumina beads from leaving the tank with the lower flow distribution plate supporting the weight of the alumina beads. Preliminary dimensions and a diagram of the thermocline tank are shown in Table 2 and Figure 5, respectively. It is important to note that the height of the tank will depend on which pipe schedule is selected for the final design. Figure 5 provides an example based on the application of schedule 40 dimensions to the tank. Since TEDS is a low-pressure system, the pipe schedule will likely be smaller, on the order of schedule 10 or 20.

The thermocline tank will be capable of operating in either a charging or discharging mode. During charging mode, the tank will behave as a heat sink. Valves BV-006, GBV-202, and GBV-203 will be closed, with GBV-201 and GBV-204 remaining open. This will allow the hot oil to transfer its heat to the alumina beads until an equilibrium temperature has been reached and the system has reached its storage capacity. Similarly, during discharging mode, the TES can act as a heat source by having valves GBV202 and GBV 203 opened, with GBV-201 and GBV-204 closed and with BV-006 being either opened or closed. This will cause the cooler oil to flow from the bottom to the top of the tank. This will continue until the outlet temperature at the top of the tank reaches $325^{\circ} \mathrm{C}$ and starts to decrease until a cutoff temperature is reached. This cutoff temperature will vary based on testing performed with the TES. 
Table 2. Potential thermocline tank heights.

\begin{tabular}{|c|c|c|c|c|c|}
\hline \multicolumn{7}{|c|}{ Thermocline Tank Dimensions } \\
\hline NPS [in] & \multicolumn{5}{|c|}{ Schedule } \\
\hline 36 & 10 & STD & 20 & 30 & 40 \\
\hline $\mathrm{D}_{\mathrm{o}}[\mathrm{in}]$ & 36 & 36 & 36 & 36 & 36 \\
\hline $\mathrm{t}[\mathrm{in}]$ & 0.312 & 0.375 & 0.50 & 0.625 & 0.75 \\
\hline $\mathrm{D}_{\mathrm{i}}[\mathrm{in}]$ & 35.38 & 35.25 & 35.00 & 34.75 & 34.50 \\
\hline Area $\left[\mathrm{in}^{2}\right]$ & 982.90 & 975.91 & 962.11 & 948.42 & 934.82 \\
\hline Alumina Section Volume $\left[\mathrm{m}^{3}\right]$ & \multicolumn{5}{|c|}{2.14} \\
\hline Total Volume $\left[\mathrm{m}^{3}\right]$ & \multicolumn{5}{|l}{} \\
\hline Distribution Plate Distance $[\mathrm{in}]$ & 16.61 & 16.73 & 16.97 & 17.21 & 17.46 \\
\hline Total Height [in] & $\mathbf{1 6 6 . 0 8}$ & $\mathbf{1 6 7 . 2 7}$ & $\mathbf{1 6 9 . 6 7}$ & $\mathbf{1 7 2 . 1 2}$ & $\mathbf{1 7 4 . 6 2}$ \\
\hline
\end{tabular}

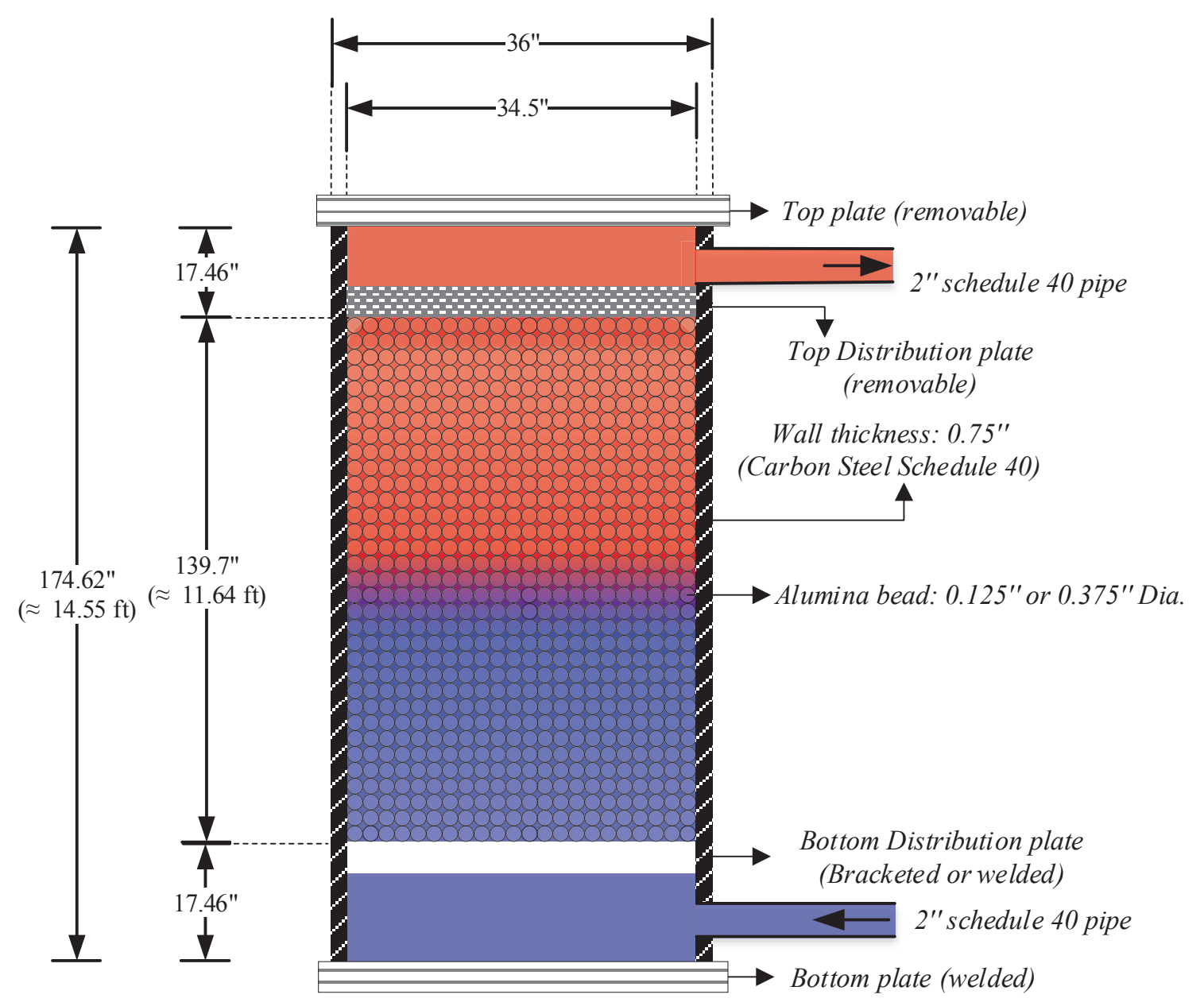

Figure 5. Potential thermocline tank dimensions. 


\subsubsection{Piping and Insulation}

Piping in the TEDS loop will be constructed of carbon steel, which is compatible with Therminol 66 and can meet the design conditions. This pipe size was selected based on a comparison of pressure drop, fluid velocity, and loop time constant for various nominal pipe sizes (NPS). Possible sizes range from 1 to 3 -inches. A NPS of 2-inches had optimal values for all parameters and offered a reduced pressure drop $(\approx$ $2-7$ psi) while maintaining an adequate loop time constant $(\approx 2-4$ minutes $)$. These parameters are compared with values calculated for other pipe sizes in Table 3 and Table 4 . These parameters were calculated for flowrates needed to heat the oil from 225 to $325^{\circ} \mathrm{C}$ from either $200 \mathrm{~kW}$ or $400 \mathrm{~kW}$ heat input into the system (with properties averaged over the temperature range), respectively. The specific pipe schedule will be decided by INL engineering services, which is designing the piping system between the loop's components.

Table 3. Pipe size information for $200 \mathrm{~kW}$ heat input.

\begin{tabular}{|c|c|c|c|c|c|}
\hline \multicolumn{7}{|c|}{ Heat Input 200 [kW] | Volume Flow Rate: 15.48 [gpm] } \\
\hline NPS [in] & 1 & $11 / 2$ & 2 & $21 / 2$ & 3 \\
\hline $\mathrm{D}[\mathrm{m}]$ & 0.0254 & 0.0381 & 0.0508 & 0.0635 & 0.0762 \\
\hline $\mathrm{A}\left[\mathrm{m}^{2}\right]$ & $5.1 \mathrm{E}-04$ & $1.1 \mathrm{E}-03$ & $2.0 \mathrm{E}-03$ & $3.2 \mathrm{E}-03$ & $4.6 \mathrm{E}-03$ \\
\hline $\mathrm{v}[\mathrm{m} / \mathrm{s}]$ & 1.9 & 0.9 & 0.5 & 0.3 & 0.2 \\
\hline $\mathrm{Re}$ & 84,305 & 56,203 & 42,152 & 33,722 & 28,102 \\
\hline $\mathrm{t}[\mathrm{s}]$ & 62 & 141 & 250 & 390 & 562 \\
\hline $\mathrm{t}[\mathrm{min}]$ & 1.04 & 2.34 & 4.16 & 6.51 & 9.37 \\
\hline $\boldsymbol{\Delta} \mathbf{P}[\mathbf{p s i}]$ & $\mathbf{5 6 . 8 7}$ & $\mathbf{6 . 9 1}$ & $\mathbf{1 . 6 1}$ & $\mathbf{0 . 5 3}$ & $\mathbf{0 . 2 2}$ \\
\hline
\end{tabular}

Table 4. Pipe size information for $400 \mathrm{~kW}$ heat input.

\begin{tabular}{|c|c|c|c|c|c|}
\hline \multicolumn{7}{|c|}{ Heat Input 400 [kW] } & Volume Flow Rate: 30.96 [gpm] \\
\hline $\mathrm{NPS}[\mathrm{in}]$ & 1 & $11 / 2$ & 2 & $21 / 2$ & 3 \\
\hline $\mathrm{D}[\mathrm{m}]$ & 0.0254 & 0.0381 & 0.0508 & 0.0635 & 0.0762 \\
\hline $\mathrm{A}\left[\mathrm{m}^{2}\right]$ & $5.1 \mathrm{E}-04$ & $1.1 \mathrm{E}-03$ & $2.0 \mathrm{E}-03$ & $3.2 \mathrm{E}-03$ & $4.6 \mathrm{E}-03$ \\
\hline $\mathrm{V}[\mathrm{m} / \mathrm{s}]$ & 3.9 & 1.7 & 1.0 & 0.6 & 0.4 \\
\hline $\mathrm{Re}$ & 168,610 & 112,406 & 84,305 & 67,444 & 56,203 \\
\hline $\mathrm{t}[\mathrm{s}]$ & 31 & 70 & 125 & 195 & 281 \\
\hline $\mathrm{t}[\mathrm{min}]$ & 0.52 & 1.17 & 2.08 & 3.25 & 4.68 \\
\hline $\mathbf{\Delta P}[\mathbf{p s i}]$ & $\mathbf{2 2 6 . 1 6}$ & $\mathbf{2 7 . 3 3}$ & $\mathbf{6 . 3 3}$ & $\mathbf{2 . 0 6}$ & $\mathbf{0 . 8 4}$ \\
\hline
\end{tabular}

\subsubsection{Oil-to-Air Heat Exchanger/Dummy Load}

An oil-to-air heat exchanger will act as a heat sink/heat control unit for the loop. For the first phase/shakedown testing of the loop, this heat exchanger will act as a "dummy load," which is meant to act as a heat consumer for TEDS. This heat exchanger will be installed outside of the ESL D100 high bay with an air blower to remove the heat. It will require a $200 \mathrm{~kW}$ heat duty to remove heat input by the MOS heater system. Because Therminol 66 has a freezing point of $-3^{\circ} \mathrm{C}$, heat tracing will be implemented on the piping to prevent potential freezing of the oil during the winter.

\subsubsection{Expansion Tank}

A 120-gallon expansion tank will be used to accommodate Therminol 66 expansion, function as a knock-out tank to remove dissolved gases (such as air) from the oil, and maintain system pressure. This 
will require the tank to be located at the highest elevation point in the system, which is recommended by Chromalox to be at least 15 feet from the bottom of the tank to the pump. This will provide adequate net positive suction head due to its location on the suction side of the pump.

\subsubsection{Storage Tanks}

The oil will be stored in two 500-gallon tanks that are unpressurized and open to atmosphere. These tanks will be used as a reservoir for any oil vented from high points in the piping and components. The system will be filled from and drained to these tanks. Similar to the manufacturing of the thermocline tank, a pipe of 36-inch NPS will be used to construct the main body of the tanks. Preliminary diagrams and dimensions of the thermocline tank have been determined and are shown in Table 5 and Figure, respectively. It is important to note that the height of the tank will depend on which pipe schedule is selected for the final design. Figure shows what the dimensions from Table 5 would look like when schedule 40 is applied to the tank and is just an example. Because the storage tanks are not sealed vessels, are unpressurized, and are open to atmosphere, the pipe schedule would likely be schedule 10 . The various schedules and corresponding dimensions are for reference purposes when obtaining manufacturing quotes.

Table 5. Potential storage tank heights.

\begin{tabular}{|c|c|c|c|c|c|}
\hline \multicolumn{7}{|c|}{ Storage Tank Dimension } \\
\hline NPS [in] & \multicolumn{7}{|c|}{ Schedule } \\
\hline 36 & 10 & STD & 20 & 30 & 40 \\
\hline $\mathrm{D}_{\mathrm{o}}[\mathrm{in}]$ & 36 & 36 & 36 & 36 & 36 \\
\hline $\mathrm{t}[\mathrm{in}]$ & 0.312 & 0.375 & 0.500 & 0.625 & 0.750 \\
\hline $\mathrm{D}_{\mathrm{i}}[\mathrm{in}]$ & 35.38 & 35.25 & 35.00 & 34.75 & 34.50 \\
\hline Area $\left[\mathrm{in}^{2}\right]$ & 982.90 & 975.91 & 962.11 & 948.42 & 934.82 \\
\hline Tank Vol $[\mathrm{gal}]$ & \multicolumn{5}{|l}{500} \\
\hline Volume $\left[\mathrm{m}^{3}\right]$ & $\mathbf{1 1 7 . 5 1}$ & $\mathbf{1 1 8 . 3 5}$ & $\mathbf{1 2 0 . 0 5}$ & $\mathbf{1 2 1 . 7 8}$ & $\mathbf{1 2 3 . 5 5}$ \\
\hline Height $[\mathrm{in}]$ &
\end{tabular}




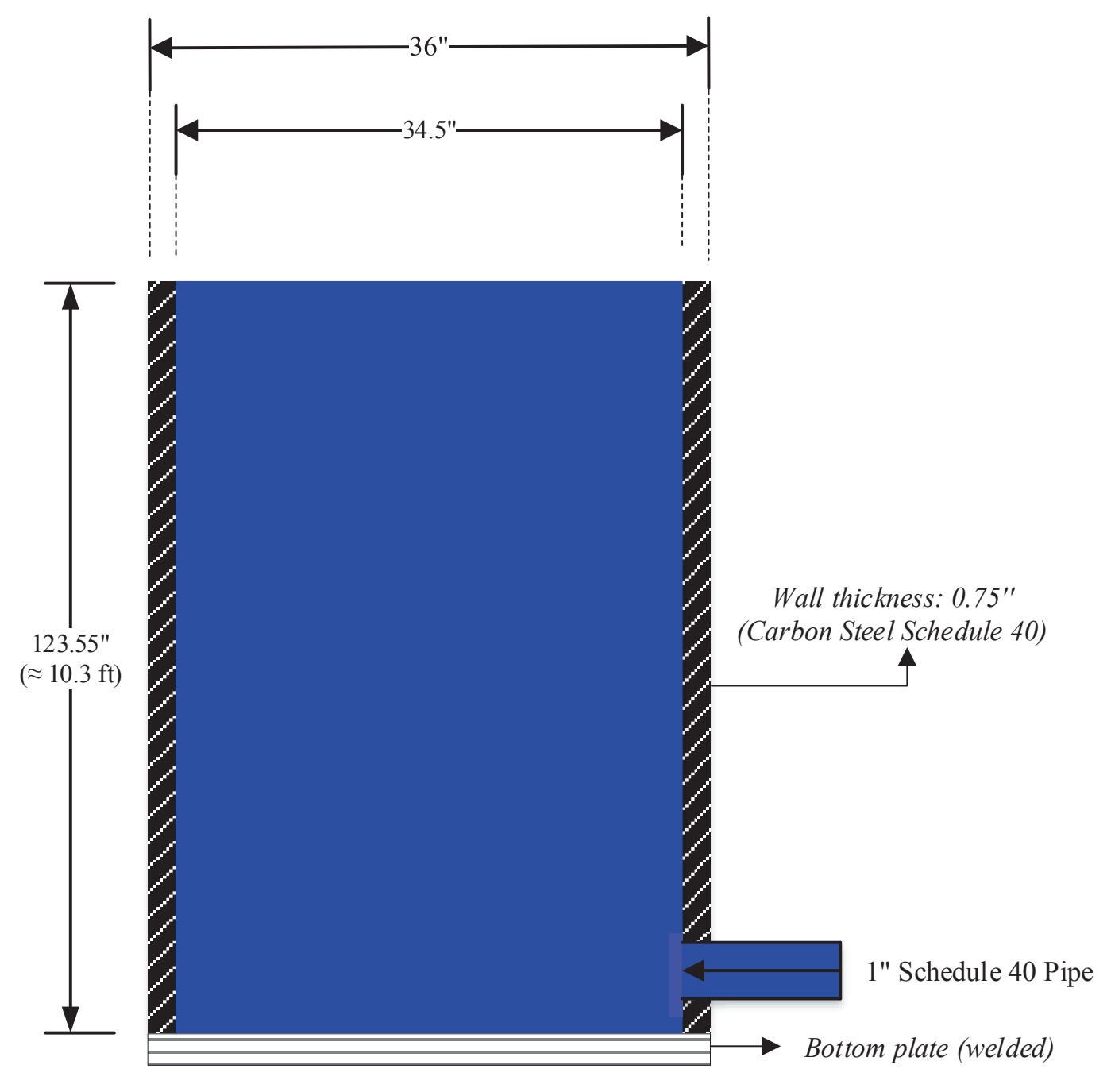

Figure 6. Potential storage tank dimensions.

\subsection{Instrumentation}

To monitor system parameters, a combination of flow sensors, pressure sensors, and thermocouples will be utilized. RTDs were considered but were not selected due to cost. Table 6 shows potential thermocouples, flowmeters, and pressure transmitters capable of functioning with the TEDS loop. Omega brand thermocouples were selected due to availability, familiarity, short lead time, and their widespread use. For the TEDS loop, the Quick Disconnect-Standard Size Molded Connector thermocouple will be used. This is because of the low-cost, durability, and versatility when compared with similar thermocouples. The 12-inch length was selected to allow the probe tip to reach the centerline of the 3-inch NPS diameter. The stainless steel construction will allow the probe to operate up to $1,250^{\circ} \mathrm{C}$. This is more than capable of handling the maximum $325^{\circ} \mathrm{C}$ operating temperature. Because the connector body is rated to $180^{\circ} \mathrm{C}$, the 12 -inch length will provide enough distance from the operating temperature that the connector body will not overheat and exceed its $180^{\circ} \mathrm{C}$ rating.

Note: Sheath diameters were quoted at 1/8-inch because this diameter is common and various sheath diameters did not change pricing. 
Parameters considered for flow meter selection included process temperatures, maximum pressure, cost, turn-down ratio, and instrument accuracy. Because flow meters need to be installed in-line with the piping, the biggest selection criteria was identifying flow meters capable of handling the high $325^{\circ} \mathrm{C}$ temperatures. Since the facility is low pressure, maximum pressure was not a key criteria in evaluating different meters. Both flow meters from Flow Technology and General Electric (GE) are capable of functioning in the operating condition range. Both have high burst pressures and similar turndown ratios, and provide a 4-20 mA output. The FT series flowmeter offered by Flow Technology has superior accuracy compared with the Panaflow MV-80 meter from GE and comes calibrated for Therminol-66. The Panaflow meter can be ordered with calibration for Therminol-66 for an additional cost. An advantage to using the Panaflow meter is its included transmitter, which is separate for the FT series meter. Additionally, the MV80 transmitter is a 4-20 mA output with a HART protocol, which will enable in-field communication with the device to verify if the instrument is within its calibration specification or out of tolerance.

The Flow Technology FT series meter is a turbine flow meter, while the GE Panaflow MV80-V is a vortex flow meter. Typically, turbine meters are susceptible to decreased accuracy when the flow is not completely clean. Considering that Therminol-66 will flow through a thermocline system, there is a chance that debris from the alumina beads will be carried throughout the system, potentially decreasing meter performance. Because the MV80-V is a vortex meter, it is less susceptible to flow debris. Additionally, the MV80-V vortex meter has no moving parts. Due to the lower cost, lack of moving parts, and HART protocol, the GE Panaflow MV80 Vortex flow meter was selected for use in the TEDS facility.

Selection of the pressure meters applied the decision criteria of maximum pressure, accuracy, operating temperature limits, signal output, and cost. There are three types of pressure transmitters used throughout the TEDS loop: differential pressure, static gauge pressure, and level differential pressure. The differential pressure transmitters evaluated are shown in Table 6 . The transmitters need to be capable of handling operating temperatures in the facility of 225 to $325^{\circ} \mathrm{C}$. Typically, transmitters are not capable of directly handling these high temperatures without incurring a large cost for the instrument materials. Sensing lines, also known as impulse lines, are used to distance the transmitter from the process temperature. This allows the fluid to cool by roughly $100^{\circ} \mathrm{F}\left(\sim 38^{\circ} \mathrm{C}\right)$ per foot, which allows the Therminol-66 to cool within the transmitters' operating range. The length of the sensing lines will be long enough to reduce the temperature, but short enough to prevent damping of the pressure signal.

Differential transmitters from Rosemount and Omega were considered because of their similar capability to meet the pressure range, accuracy, and signal output requirements. Due to the reduced cost, the Omega PX81 transmitter was selected for the differential pressure meters. Honeywell was selected for the gauge pressure meter because of its cost, accuracy, and pressure range. While this meter has the lowest operating range and would require longer sensing lines, the cost of longer tubing would be far less than the increased cost of the Rosemount. A piezoelectric pressure meter from PCB Electronics was also considered. Piezoelectric pressure meters have difficulty operating in steady-state conditions and are better for systems with fast transients, such as shock tubes. TEDS is not expected to operate under such small time scales that the Honeywell meter would be incapable of accurately capturing pressure changes. The Omega PX81 pressure transmitter was selected for the level differential pressure meter because of its use for the differential meter and the limited selection for level differential meters.

The thermocline tank will be further instrumented with strain gauges to monitor the vessel for thermal ratcheting resulting from thermal expansion of the vessel and shifting of the packed pebble bed. Multijunction thermocouples will be installed from radial instrumentation ports at various heights to provide both radial and axial temperature profiles in the pebble bed. A fiber optic temperature measurement system will be installed to demonstrate a more novel, advanced instrumentation system. 


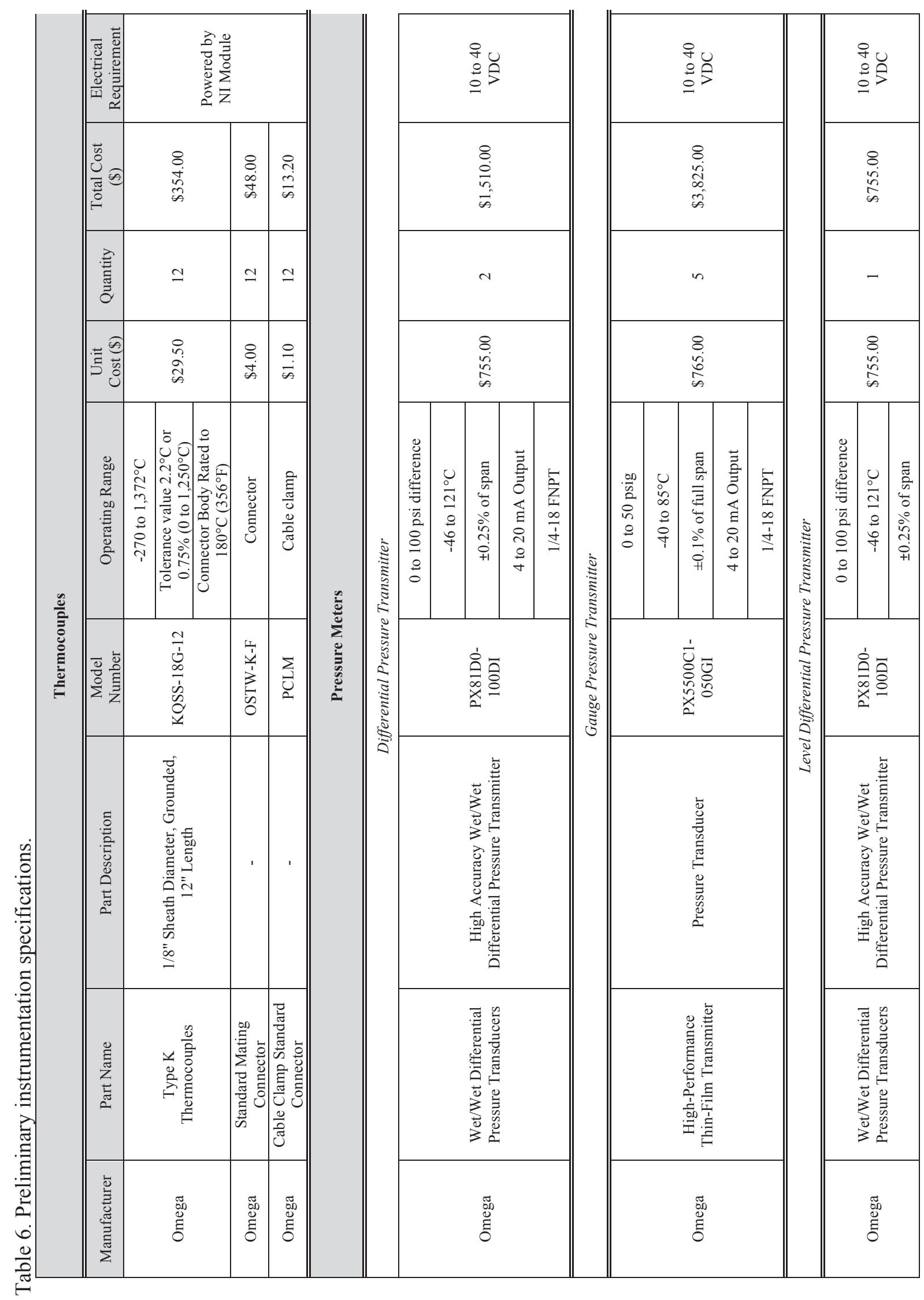




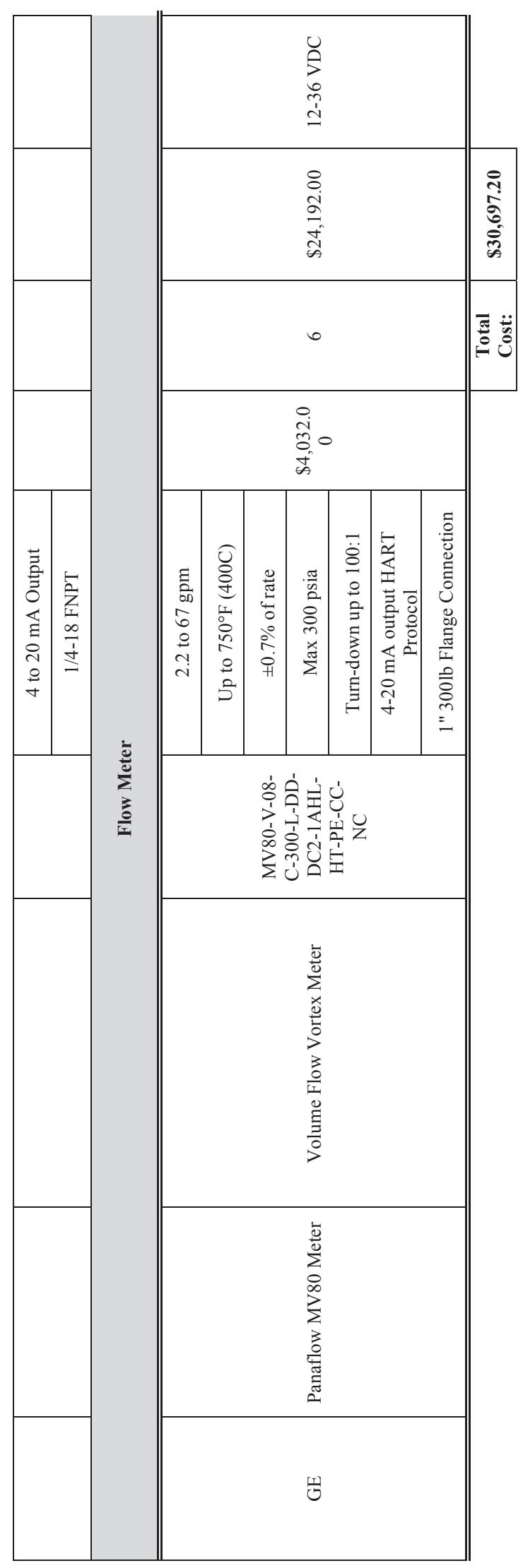




\section{Project Status}

Preliminary design of the TEDS loop has been completed, with instrumentation specifications and system component requirements identified. Chromalox has been identified as the vendor for the heater system and oil pump. A visit to Chromalox occurred on July 31, 2018, during which a MOS heater was shown to visiting members of the TEDS project, as shown in Figure 7. The team held a meeting with Chromalox representatives to discuss requirements for the heater.

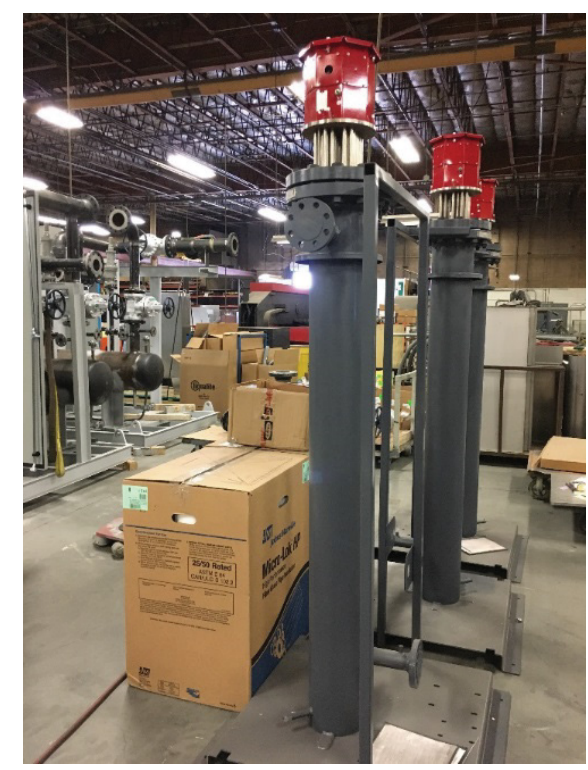

Figure 7. MOS heater from Chromalox tour.

The operating conditions and design requirements have been identified and documented in functional and operational document FOR-415, which has been through a review process in the electronic change request (eCR) system (see Appendix A). Comments from this review process were incorporated into the final version of FOR-415 and entered into the INL Electronic Document Management System (EDMS). The functional and operational document was submitted to engineering services and is being used to design the piping, necessary support structures, and utilities needed for the operation of the TEDS loop. A design review including both internal and external stakeholders will be held for the TEDS design prior to finalizing the design and moving forward with procurement.

\section{Summary}

A preliminary design for the Thermal Energy Delivery System has been completed. A finalized P\&ID has been developed to allow the loop to flexibly operate between charging/discharging modes of a thermal energy storage system and delivering process heat for high-temperature steam electrolysis and a heat sink/simulated heat load. Instrumentation to observe the system dynamics has been specified and will be used with a LabVIEW data acquisition system to record data and implement a control system. 
Appendix A

\section{Functional \& Operational Requirements}




\section{Functional and Operational Requirements}

\section{Thermal Energy Delivery System}

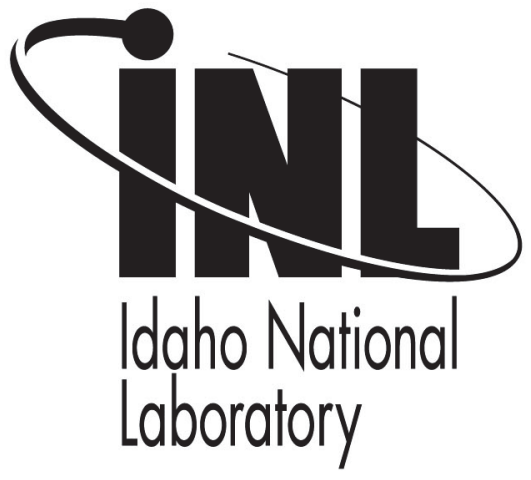

The INL is a U.S. Department of Energy National Laboratory operated by Battelle Energy Alliance. 


\begin{tabular}{|c|lll|}
\hline THERMAL ENERGY DELIVERY & Identifier: & FOR-415 & \\
SYSTEM & Revision: & 1 & \\
& Effective Date: & $08 / 30 / 18$ & Page: 2 of $\mathbf{3 0}$ \\
\hline
\end{tabular}

\begin{tabular}{|l|l|l|l|}
\hline Applicability: Laboratory-wide & Functional and Operational Requirements & & eCR Number: 662465 \\
\hline
\end{tabular}

Management System: Engineering

\section{CONTENTS}

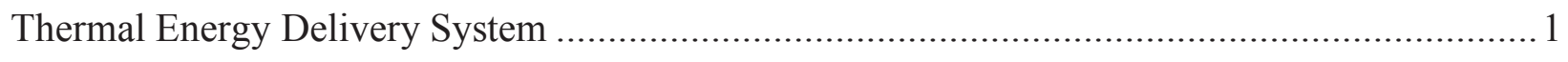

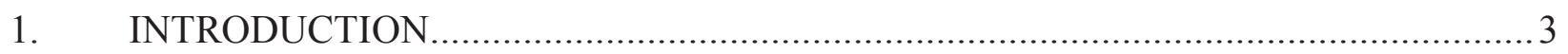

1.1 Description of Engineering Task ......................................................... 3

1.2 Description of the End-Use for the Engineered Item or Activity....................... 3

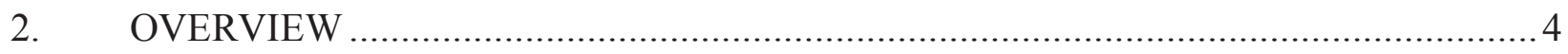

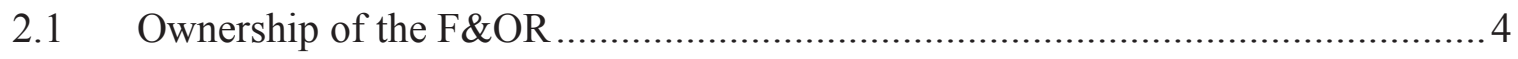

2.2 End-User of Engineered Item or Activity .................................................. 4

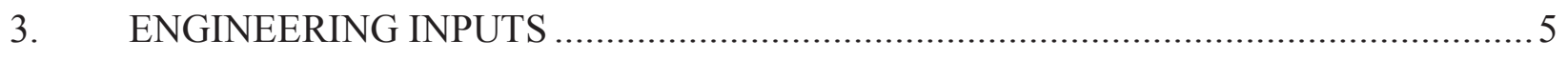

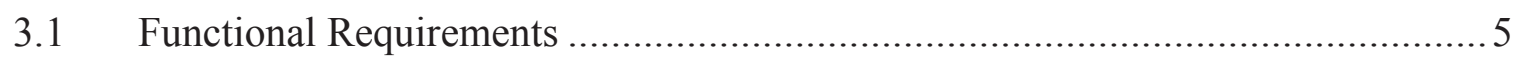

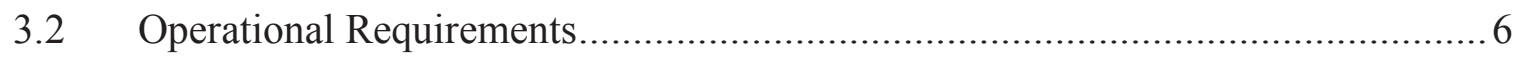

3.3 Owner Specified Technical Requirements.................................................. 8

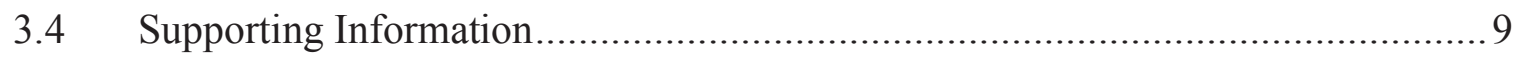

3.4.1 Need for Configuration Management ............................................ 9

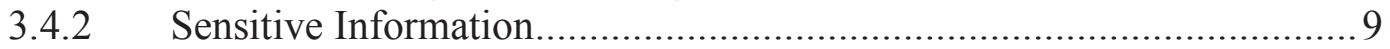

Export Control...................................................................... 9

3.4.4 Need for Engineering Change Control ............................................ 9

3.4.5 Level of Verification Needed ................................................ 9

3.4.6 Technical Integrator .......................................................... 9

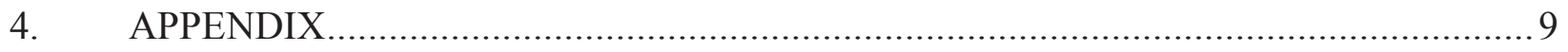

Appendix A Charts, Diagrams, and Lists ................................................... 10

MOS Heater System Drawings: ......................................................... 14

Potential MOS Pump Curves and Datasheet............................................ 15

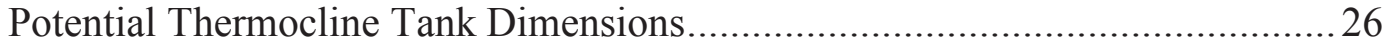

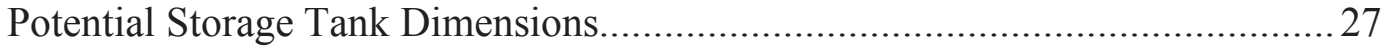

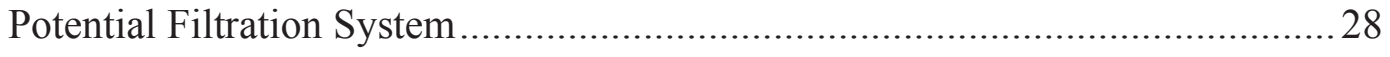

Appendix B Instrumentation Specifications .......................................................29 


\begin{tabular}{|c|lll|}
\hline THERMAL ENERGY DELIVERY & Identifier: & FOR-415 & \\
SYSTEM & Revision: & 1 & \\
& Effective Date: & $08 / 30 / 18$ & Page: 3 of $\mathbf{3 0}$ \\
\hline
\end{tabular}

\section{INTRODUCTION}

\subsection{Description of Engineering Task}

The Thermal Energy Delivery System (TEDS) will be a thermal hydraulic flow loop with a stand-alone dedicated control system to support test/demonstration operations for DETAIL and Nuclear-Renewable Hybrid Energy System (N-R HES) applications. This Functional and Operational Requirements document is requesting the design of piping/insulation between flow loop equipment, necessary support structures, and utilities needed for the operation of TEDS.

\subsection{Description of the End-Use for the Engineered Item or Activity}

TEDS will have the capability of modulating the flow rate and temperature of the heat transfer medium and be able to divert thermal energy as required by heat customers. The heat transfer medium used in TEDS will be a high-performance, highly stable synthetic heat transfer oil (Therminol 66). A schematic of the TEDS loop is shown in Figure 1. Further information on the functional and operational requirements is described in Section 3. The TEDS facility will be located within the Energy Systems Laboratory (ESL) D100 northwest high bay.

TEDS will be able to deliver required process heat supply to heat consumers/customers, demonstrate associated transport/transmission characteristics and performance in a flexible and dynamic manner, such that envisioned operational modes can be tested and performance verified. Experimental performance of TEDS will allow for better modeling of integrated systems and provide experimental data for validation of computational models. This would include providing information on time constants, which would aid in parametric studies for further improvements and optimization. The outcomes of this project will help understand the cyclic behavior (charging and discharging characteristic) of an energy storage system and the system dynamic behavior with integrated industrial applications, and provide much-needed feedback for control systems to support DETAIL test/demonstration operations.

This facility will enhance the existing INL core research capability of being able to design thermal capacitors that would optimize high-temperature thermal energy utilization, thus assisting research in nuclear reactor industry and heat transport/delivery systems. The project will support systems integration, flexible operation, dynamic model validation, and technical performance characterization of envisioned scenarios to support DETAIL test/demonstration operations. The loop can be further expanded to integrate additional future systems with minimal disruptions to TEDS operation by having a control strategy in place to divert the flow as required and adjust the temperature and flow rate, accordingly. 


\begin{tabular}{|c|lll|}
\hline THERMAL ENERGY DELIVERY & Identifier: & FOR-415 & \\
SYSTEM & Revision: & 1 & \\
& Effective Date: & $08 / 30 / 18$ & Page: 4 of $\mathbf{3 0}$ \\
\hline
\end{tabular}

\section{OVERVIEW}

\subsection{Ownership of the F\&OR}

Dr. James O'Brien is the principle investigator/principal researcher and owner of the functional and operational requirements document.

\subsection{End-User of Engineered Item or Activity}

The end user of the facility will be Dr. James O'Brien. The ESL building is maintained by Facilities and Site Services. 


\begin{tabular}{|c|lll|}
\hline THERMAL ENERGY DELIVERY & Identifier: & FOR-415 & \\
SYSTEM & Revision: & 1 & \\
& Effective Date: & $08 / 30 / 18$ & Page: 5 of $\mathbf{3 0}$ \\
\hline
\end{tabular}

\section{ENGINEERING INPUTS}

The designed TEDS facility shall be capable of meeting the following functional and operational requirements.

\subsection{Functional Requirements}

- The $200 \mathrm{~kW}$ thermal energy delivery system shall include a $200 \mathrm{~kW}$ oil heating unit, which shall supplement future heat delivery from the PWR water loop when available, with similar heat duty.

- The oil heating system shall allow for monitoring/control of heater electrical power level.

- The system shall be designed to support unattended operation with remote alarm capability.

- An air-to-oil heat exchanger shall be used as a heat sink/heat control unit for TEDS and shall be located outside.

- An appropriately sized oil circulation pump with a variable frequency drive shall provide flow through the system.

- An expansion tank shall be used to accommodate the Therminol 66's expansion, function as a knock-out tank to remove dissolved gases such as air from the oil, and maintain system pressure. This requires the expansion tank to be located at the highest elevation point in the system.

- The expansion tank shall be capable of venting to the storage tank.

- Piping and components shall have capability to vent highpoints to the storage tank.

- Piping shall have instrumentation ports to accommodate thermocouples and pressure sensing lines. Flowmeters shall be installed in-line as flanged components with appropriate gaskets.

- Thermocouple instrumentation ports shall be able to accommodate multiple thermocouples in each port.

- Piping shall have sufficient insulation to prevent heat loss to the environment and protect personnel.

- Pressure sensing lines shall have isolation valves and bleed valves to isolate pressure instrumentation and allow lines to be drained.

- Valved-off blind flanges shall be designed to accommodate a future interface with potential systems with minimal disruptions to TEDS operation.

- Valves should be configured on piping as shown in Figure 1 and Table 2.

- Valves shall be capable of remote control as described in Table 2.

- System shall be capable of filling and draining the oil with the oil pump.

- Wire ways shall be installed to allow wiring paths for instrumentation and valve controls.

- Flow analysis of the system shall be performed upon completion of physical layout and design.

- Loop shall be capable of being completely drained to the storage tank.

- TEDS loop shall be placed on a skid with a no-slip material.

- System shall be analyzed and designed to accommodate thermal stresses in the piping system. 


\section{THERMAL ENERGY DELIVERY SYSTEM}

$\begin{array}{ll}\text { Identifier: } & \text { FOR-415 } \\ \text { Revision: } & 1 \\ \text { Effective Date: } & 08 / 30 / 18\end{array}$

\subsection{Operational Requirements}

- Design Pressure: 100 psig

- Design Temperature: $340^{\circ} \mathrm{C}$

- Nominal operation requirements for TEDS are provided below and in Table 1.

- Maximum Oil Operating Temperature: $325^{\circ} \mathrm{C}$

- Return Oil Operating Temperature: $225^{\circ} \mathrm{C}$

- Maximum Operating Pressure: 14 psig

- Nominal flow rate in TEDS: 0.8-1.62 kg/s (14-33 gpm)

- Nominal Pipe Size: 2 in.

- Electrical Requirement: 120/208/480 VAC as required for the process equipment

Table 1: TEDS Operating Requirements

\begin{tabular}{|c|c|c|}
\hline Components & Rating & Suggested Equipment/Notes \\
\hline \multirow[b]{2}{*}{ Heater } & 200 kW Output & \multirow{2}{*}{$\begin{array}{l}\text { Chromalox MOS Hot Oil } \\
\text { System, } T_{\max }=343^{\circ} \mathrm{C}\end{array}$} \\
\hline & $\begin{array}{l}\text { Electrical Requirement: } \\
480 \mathrm{~V} \text { (3 Phase) }\end{array}$ & \\
\hline Expansion Tank & $\begin{array}{c}120 \text { Gallons } \\
\text { (sized for } 200 \mathrm{~kW} \text { heater) }\end{array}$ & $\begin{array}{c}\text { Chromalox provided expansion } \\
\text { tank rated for MOS Hot Oil } \\
\text { System }\end{array}$ \\
\hline \multirow{4}{*}{ Oil Pump } & 3 HP motor & \multirow{4}{*}{$\begin{array}{l}\text { MP Pumps: HTO } 80 \text { model } \\
\text { Class } 150 \text { Flanges }\end{array}$} \\
\hline & $\begin{array}{l}\text { Motor Requirement: } \\
0-50 \mathrm{gpm}\end{array}$ & \\
\hline & $\begin{array}{l}\text { Head pressure to be determined } \\
\text { by fluid flow analysis }\end{array}$ & \\
\hline & $\begin{array}{c}\text { Controller: } \\
\text { Variable Frequency Drive (VFD) }\end{array}$ & \\
\hline $\begin{array}{l}\text { Packed Bed Thermal } \\
\text { Energy Storage }\end{array}$ & $\begin{array}{c}\text { NPS: } 36 \text { in } \\
\text { Height: } 166-175 \text { in }\end{array}$ & $\begin{array}{l}\text { Height depends on use of pipe } \\
\text { schedules such as } 10 \text { thru } 40 \text { for } \\
\text { carbon steel. }\end{array}$ \\
\hline $\begin{array}{l}\text { Heat Load (Air-to-Oil } \\
\text { HX/Dummy Load) }\end{array}$ & 200 kW Heat Duty & $\begin{array}{l}\text { Located outside, air blower will } \\
\text { need electrical power. }\end{array}$ \\
\hline Oil Storage Tank(s) & Total capacity of 1000 gallons & Open to atmosphere $\operatorname{tank}(\mathrm{s})$ \\
\hline \multirow[b]{2}{*}{ Filtration System } & \multirow[b]{2}{*}{ Rated up to $343^{\circ} \mathrm{C}$ and $150 \mathrm{psig}$} & 1-1/2" Class 300 Flanges \\
\hline & & $\begin{array}{l}\text { Liquid Process Systems, Inc. } \\
\text { Model \# VC15C-BP-F }\end{array}$ \\
\hline $\begin{array}{l}\text { Data Acquisition } \\
\text { System }\end{array}$ & $\begin{array}{l}\text { Electrical Requirement: 9-40 } \\
\text { VDC Input }\end{array}$ & $\begin{array}{l}\text { Access to } 110 \mathrm{~V} \text { outlets } \\
\text { required. }\end{array}$ \\
\hline Computer Station & $\begin{array}{l}\text { Electrical Requirement: } \\
110 \text { V Outlet }\end{array}$ & $\begin{array}{l}\text { Access to } 110 \mathrm{~V} \text { outlets } \\
\text { required. }\end{array}$ \\
\hline
\end{tabular}




\begin{tabular}{|c|lll|}
\hline THERMAL ENERGY DELIVERY & Identifier: & FOR-415 & \\
SYSTEM & Revision: & 1 & \\
& Effective Date: & $08 / 30 / 18$ & Page: 7 of 30 \\
\hline
\end{tabular}

Table 2 shows each valve listed in Figure 1 and includes the valve number, desired control method, and precision required for opening/closing each valve. Check valves are listed as uni-directional because they open with flow in one direction and prevent flow reversal, and is why they are listed as flow controlled. The only valves that are manually controlled are the isolation and bleed valves on the pressure sensing lines (not shown in Figure 1) and BV-018 is attached to the oil storage $\operatorname{tank}(\mathrm{s})$.

Table 2: Valve Description and Control Method

\begin{tabular}{|c|c|c|c|}
\hline Valve Number & Valve Type & Position(s) & Control Method \\
\hline \multicolumn{4}{|c|}{ TEDS Valves } \\
\hline CV-001 & Check Valve & Uni-directional & Flow controlled \\
\hline GBV-002 & Globe Valve & Variable & Pneumatic actuator \\
\hline BV-003 & Ball Valve & On/Off & Pneumatic actuator \\
\hline GBV-004 & Globe Valve & Variable & Pneumatic actuator \\
\hline $\mathrm{BV}-005$ & Ball Valve & On/Off & Pneumatic actuator \\
\hline BV-006 & Ball Valve & On/Off & Pneumatic actuator \\
\hline CV-007 & Check Valve & Uni-directional & Flow controlled \\
\hline BV-008 & Ball Valve & On/Off & Pneumatic actuator \\
\hline BV-009 & Ball Valve & On/Off & Pneumatic actuator \\
\hline BV-010 & Ball Valve & On/Off & Pneumatic actuator \\
\hline BV-011 & Ball Valve & On/Off & Pneumatic actuator \\
\hline GBV-012 & Globe Valve & Variable & Pneumatic actuator \\
\hline GV-013 & Gate Valve & On/Off & Pneumatic actuator \\
\hline GBV-014 & Globe Valve & Variable & Pneumatic actuator \\
\hline GV-015 & Gate Valve & On/Off & Pneumatic actuator \\
\hline GBV-016 & Globe Valve & Variable & Pneumatic actuator \\
\hline GBV-017 & Globe Valve & Variable & Pneumatic actuator \\
\hline BV-018 & Ball Valve & On/Off & Manual \\
\hline GV-019 & Gate Valve & On/Off & Pneumatic actuator \\
\hline GV-020 & Gate Valve & On/Off & Pneumatic actuator \\
\hline CV-021 & Check Valve & Uni-directional & Flow controlled \\
\hline GV-022 & Gate Valve & On/Off & Pneumatic actuator \\
\hline GV-023 & Gate Valve & On/Off & Pneumatic actuator \\
\hline $\mathrm{GV}-024$ & Gate Valve & On/Off & Pneumatic actuator \\
\hline \multicolumn{4}{|c|}{ PWR HX Valves } \\
\hline GV-101 & Gate Valve & On/Off & Electrical actuator \\
\hline GV-102 & Gate Valve & On/Off & Electrical actuator \\
\hline \multicolumn{4}{|c|}{ Thermocline Tank Valves } \\
\hline GBV-201 & Globe Valve & Variable & Pneumatic actuator \\
\hline GBV-202 & Globe Valve & Variable & Pneumatic actuator \\
\hline GBV-203 & Globe Valve & Variable & Pneumatic actuator \\
\hline GBV-204 & Globe Valve & Variable & Pneumatic actuator \\
\hline \multicolumn{4}{|c|}{ HTSE SG Valves } \\
\hline GV-301 & Gate Valve & On/Off & Electrical actuator \\
\hline GV-302 & Gate Valve & On/Off & Electrical actuator \\
\hline
\end{tabular}




\begin{tabular}{|c|lll|}
\hline THERMAL ENERGY DELIVERY & Identifier: & FOR-415 & \\
SYSTEM & Revision: & 1 & \\
& Effective Date: & $08 / 30 / 18$ & Page: 8 of $\mathbf{3 0}$ \\
\hline
\end{tabular}

\subsection{Owner Specified Technical Requirements}

- An expansion tank shall be located at the highest elevation point in the system which is assumed to be at least $15 \mathrm{ft}$ elevation from bottom of tank to the pump. It is preferred to locate the tank on the existing utility support structure for the High Temperature Steam Electrolysis while considering design of the system.

- Air-to-Oil heat exchanger needs to be rated to a heat duty of $200 \mathrm{~kW}$, located outside, and not allow the Therminol 66 to freeze.

- Piping, flanges, and tank material are assumed to be carbon steel.

- Piping shall comply with ASME 31.3 Process Piping Code

- Thermal Energy Storage tank shall be an ASME BVPC Section 8 Division 1 vessel.

- The electrical system shall be designed to the current National Electric Code

- Layout of flow loop equipment should reference Figure 3.

- Configuration of valves should reference Figure 1.

- Pressure drop through Thermocline tank system for flow analysis will be performed/provided by the researchers.

- Project researchers shall be responsible for instrumentation and valve control wiring. 


\begin{tabular}{|c|lll|}
\hline THERMAL ENERGY DELIVERY & Identifier: & FOR-415 & \\
SYSTEM & Revision: & 1 & \\
& Effective Date: & $08 / 30 / 18$ & Page: 9 of $\mathbf{3 0}$ \\
\hline
\end{tabular}

\subsection{Supporting Information}

\subsubsection{Need for Configuration Management}

The TEDS project will require some configuration management as described in LWP-10500, and will require as built drawings.

\subsubsection{Sensitive Information}

Not applicable

\subsubsection{Export Control}

Not applicable

\subsubsection{Need for Engineering Change Control}

Not applicable

\subsubsection{Level of Verification Needed}

The TEDS project will require an electronic design review with project stakeholders.

\subsubsection{Technical Integrator}

Not applicable

\section{APPENDIX}

Appendix A: Charts, Diagrams, and Lists

Appendix B: Instrumentation Specifications 

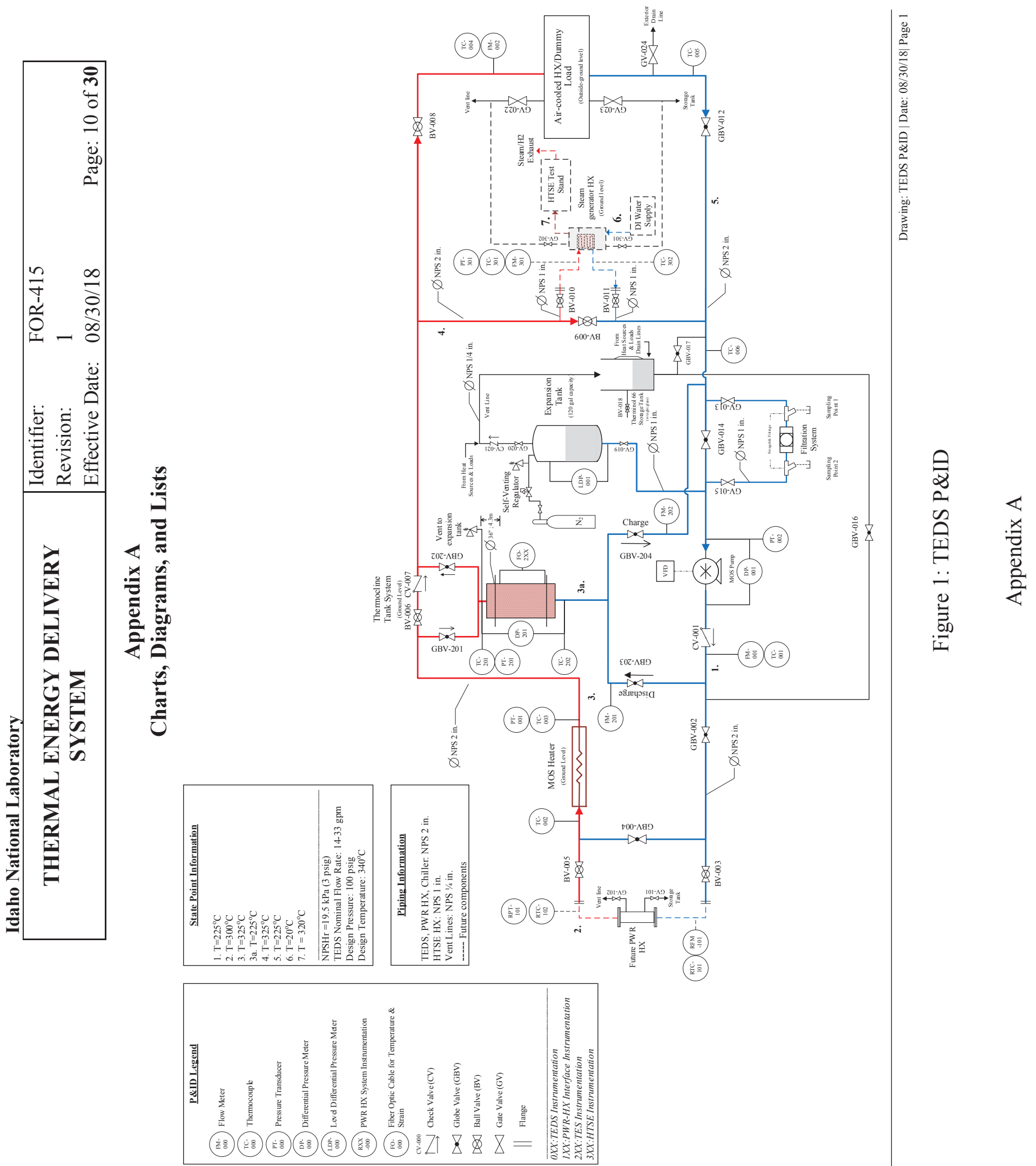

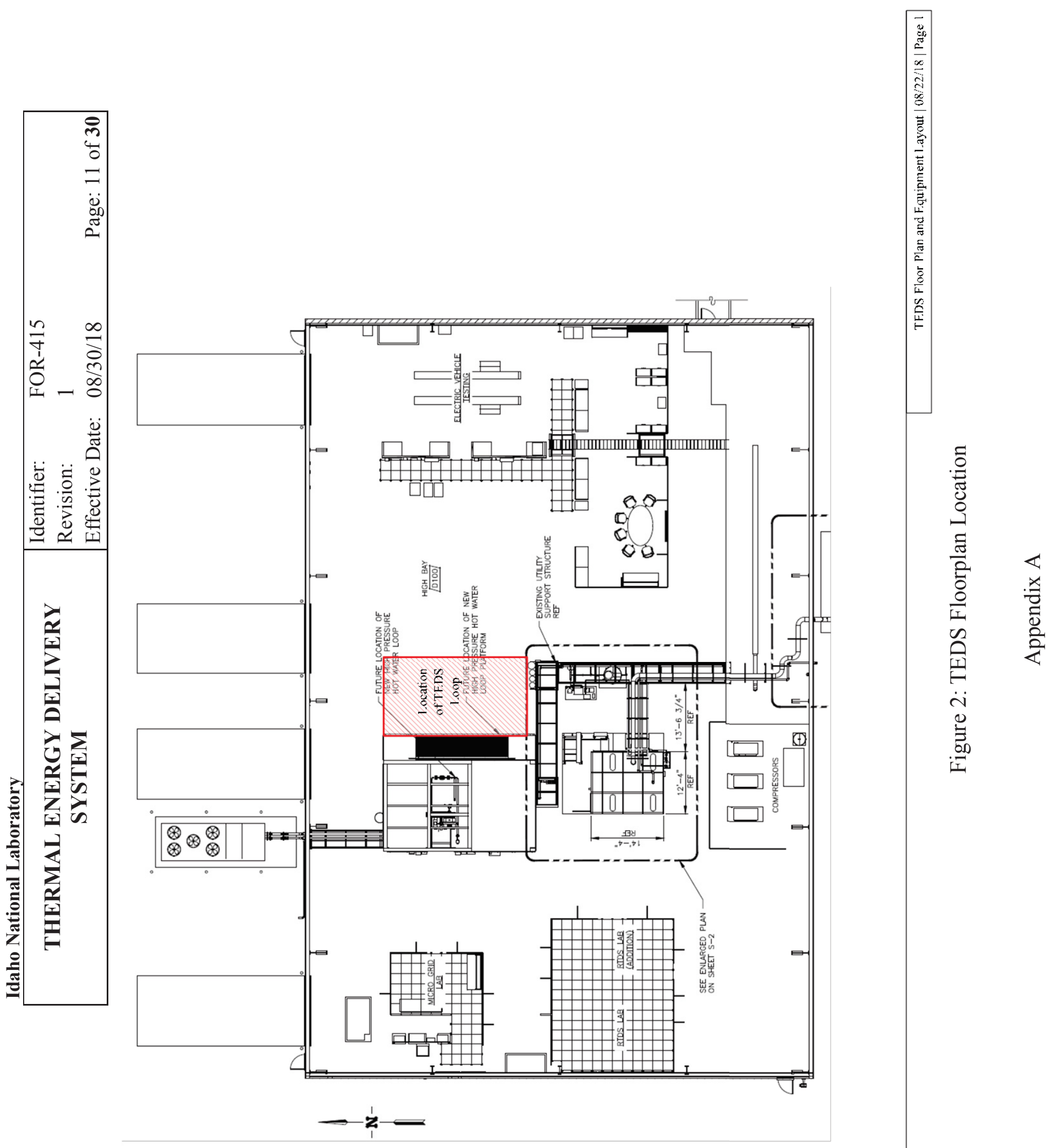


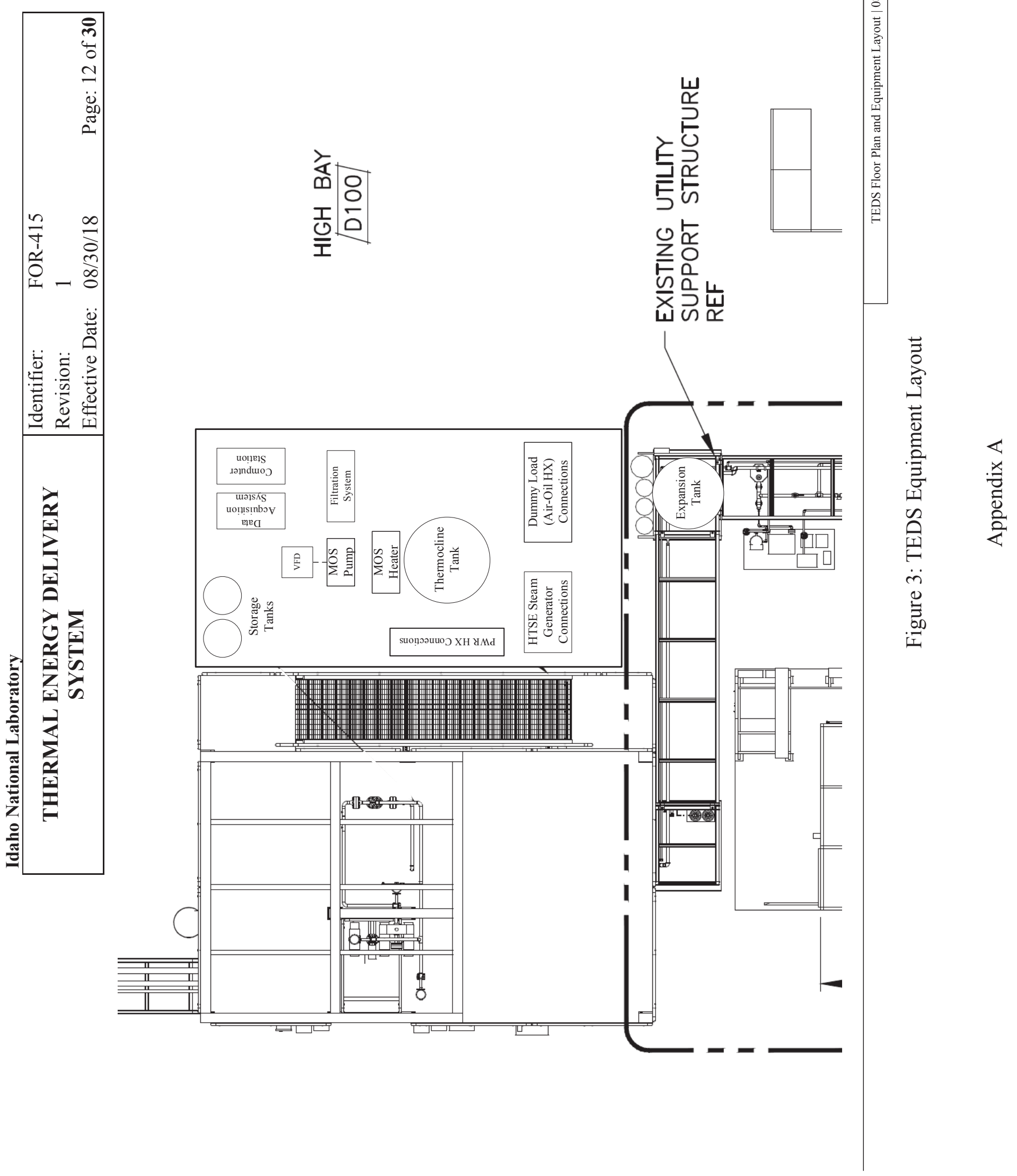




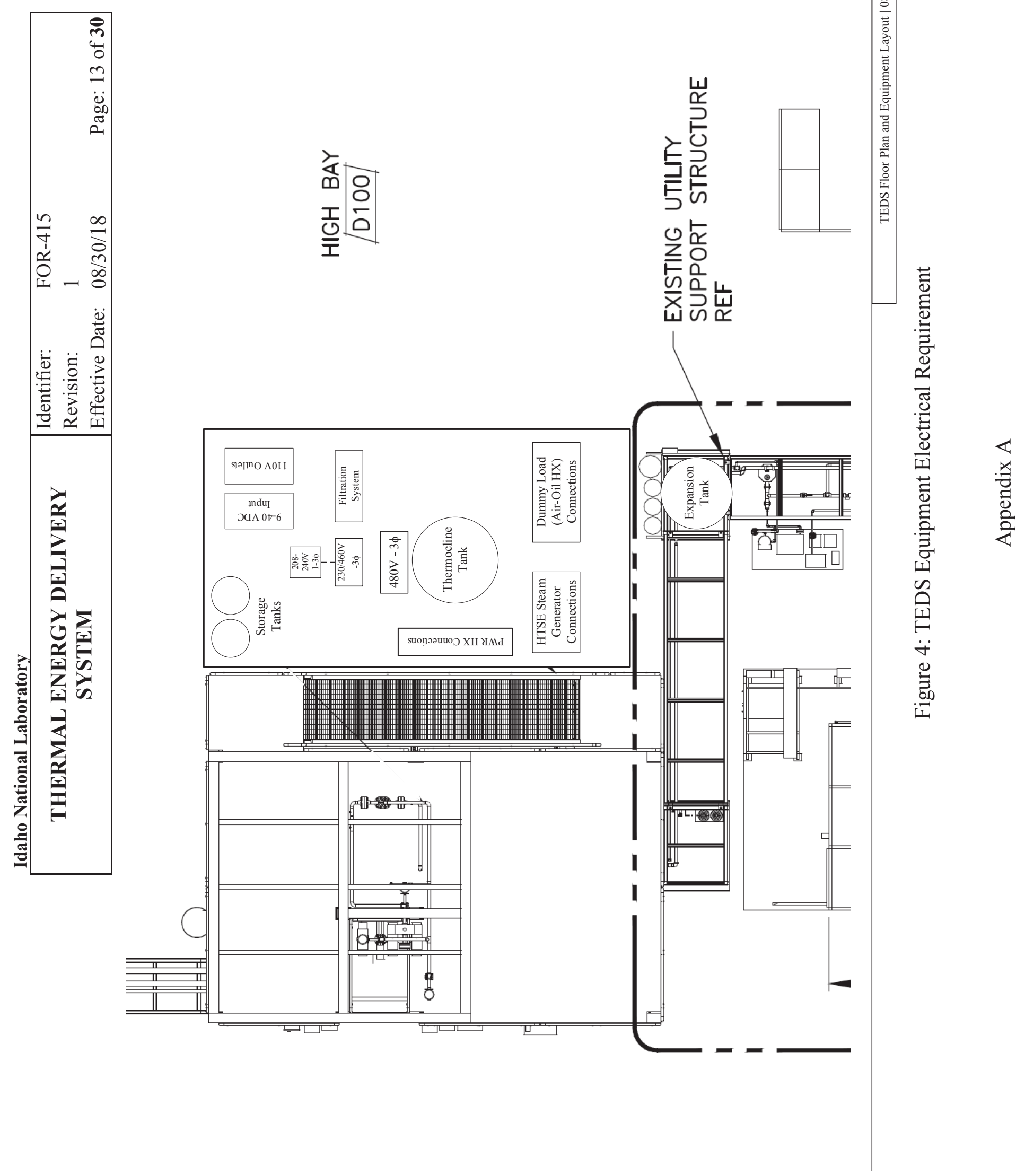


THERMAL ENERGY DELIVERY SYSTEM

$\begin{array}{ll}\text { Identifier: } & \text { FOR-415 } \\ \text { Revision: } & 1 \\ \text { Effective Date: } & 08 / 30 / 18\end{array}$

Page: 14 of $\mathbf{3 0}$

\section{MOS Heater System Drawings:}

See attached drawings detailing dimensions of the MOS heater system.

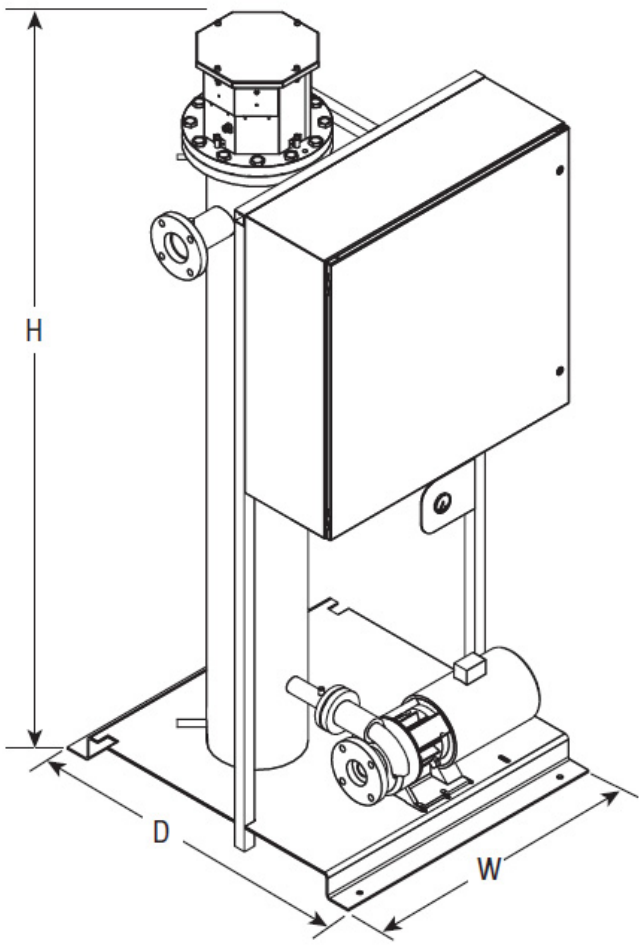

MOS 50-150 kW Unit (Front View)

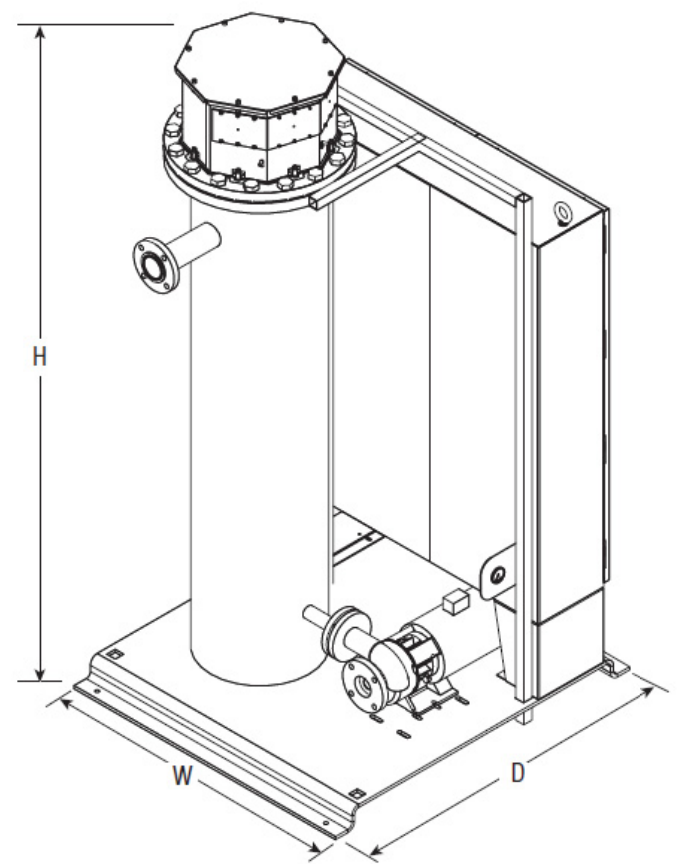

MOS 175-500 kW Unit (Rear View)

Unit Proportions

\begin{tabular}{|c|c|c|c|c|c|c|c|c|c|}
\hline Unit Size & $\begin{array}{c}\text { Dry } \\
\text { Weight } \\
\text { (Lbs.) }\end{array}$ & $\begin{array}{l}\text { Width } \\
\text { (In.) }\end{array}$ & $\begin{array}{c}\text { Depth } \\
\text { (In.) }\end{array}$ & $\begin{array}{l}\text { Height' } \\
\text { (In.) }\end{array}$ & $\begin{array}{l}\text { Flow } \\
\text { Rate }^{2} \\
\text { GPM }\end{array}$ & $\begin{array}{l}\text { Pressure }^{2} \\
\text { TDH } \\
\text { (Ft.) }\end{array}$ & $\begin{array}{l}\text { Motor } \\
\text { HP }\end{array}$ & $\begin{array}{c}\text { Inlet/Outlet } \\
\text { Connection } \\
\text { ANSI }\end{array}$ & $\begin{array}{c}\text { System } \\
\text { Capacity } \\
\text { (Gal.) }\end{array}$ \\
\hline $50 \& 75 \mathrm{~kW}$ & 900 & 36 & 42 & 96 & 80 & 130 & 5 & 2", 150\# & 24 \\
\hline $100-150 \mathrm{~kW}$ & 1400 & 36 & 42 & 96 & 120 & 130 & 7.5 & 3", 150\# & 35 \\
\hline $175-300 \mathrm{~kW}$ & 2600 & 48 & 54 & 96 & 200 & 130 & 10 & 3", 150\# & 65 \\
\hline $350-500 \mathrm{~kW}$ & 3500 & 48 & 54 & 96 & $200^{3}$ & 130 & $10^{3}$ & $3 ", 150 \#^{3}$ & 85 \\
\hline
\end{tabular}


THERMAL ENERGY DELIVERY SYSTEM
Identifier:

Revision: $\quad 1$

Effective Date: $08 / 30 / 18$

\section{Potential MOS Pump Curves and Datasheet}

\section{(MP HTO $^{\text {TM }} 80$ \\ 1-1/2" x 1-1/4" End Suction Centrifugal Hot Oil Pump}

HTO 80 is a patented, unique centrifugal pump designed for high temperature applications, such as the plastics, chemical, food and processing industries. The pump can be used in horizontal or vertical positions and is available with or without an electric motor. It is designed to greatly reduce the temperature at the seal by utilizing ambient air temperature which greatly increases seal life.

Want to learn more about using pumps with heat transfer fluids? Click here to view "Using Pumps with Heat Transfer Fluids" an article featured in Process Heating Magazine written by MP Pumps' Chief Engineer.

\section{SPECIFICATIONS:}

Suction And Discharge

Materials Of Construction

$1-1 / 2 " \times 1-1 / 4^{\prime \prime}$ NPT or flat flange option

Ductile iron

Flow Up to 85 GPM

Head Feet Up to $130^{\circ}$

Impeller $\quad 5.9^{*}$ steel, enclosed

Motor Up to $3 \mathrm{HP}$

Drive Options Close coupled 56C, Close coupled 145TC,

Seal

Carbon / silicon carbide / Viton

Temperature

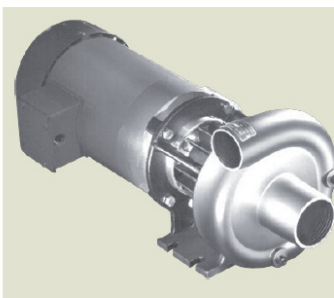

Application

-Industrial

Drive Sleeve

- Hardened 303 stainless steel

Features

- Isolated air cooled seal chamber $650^{\circ} \mathrm{F} \max$

\section{HTO тм 80}

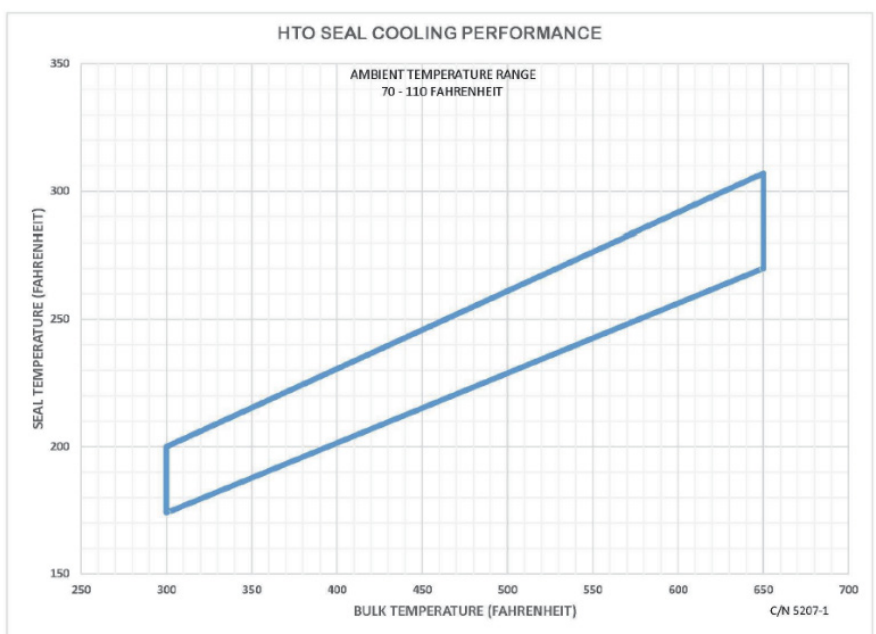




\begin{tabular}{|c|c|c|c|}
\hline $\begin{array}{c}\text { THERMAL ENERGY DELIVERY } \\
\text { SYSTEM }\end{array}$ & $\begin{array}{l}\text { Identifier: } \\
\text { Revision: } \\
\text { Effective Date: }\end{array}$ & $\begin{array}{l}\text { FOR-415 } \\
1 \\
08 / 30 / 18\end{array}$ & Page: 16 of $\mathbf{3 0}$ \\
\hline
\end{tabular}

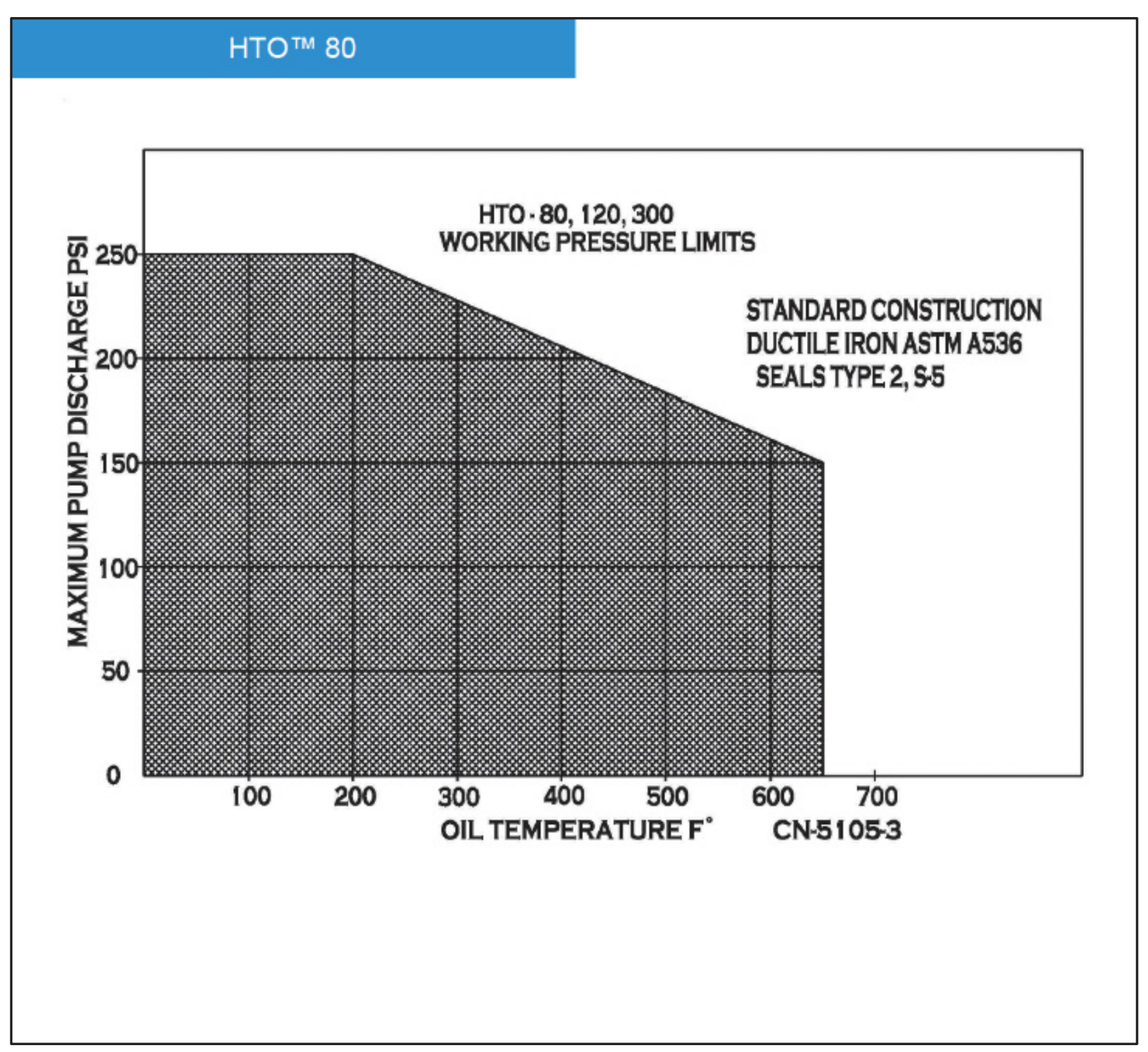


Idaho National Laboratory

\begin{tabular}{|c|lll|}
\hline THERMAL ENERGY DELIVERY & Identifier: & FOR-415 & \\
SYSTEM & Revision: & 1 & \\
& Effective Date: & $08 / 30 / 18$ & Page: 17 of 30 \\
\hline
\end{tabular}

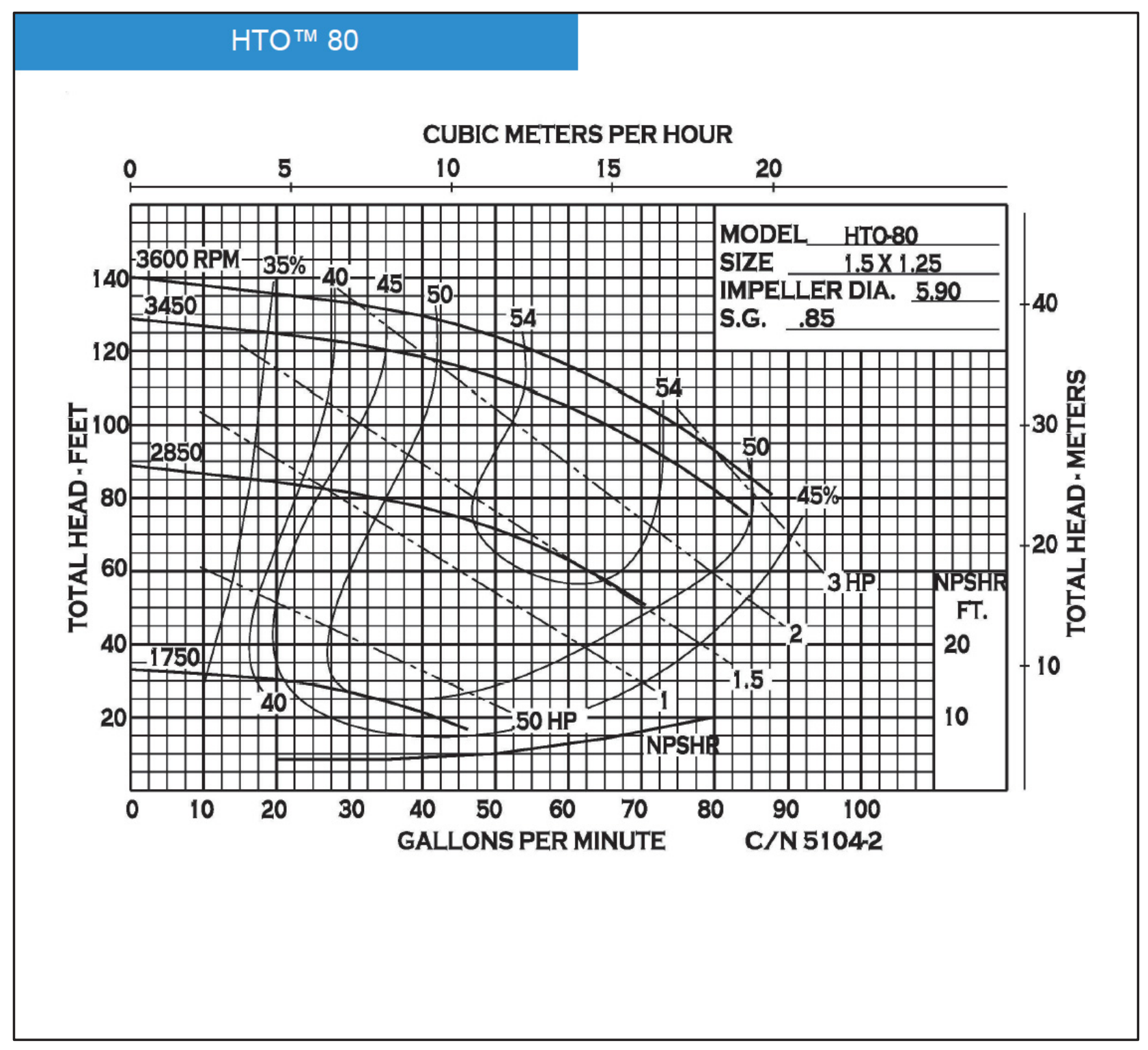

Appendix A 


\begin{tabular}{|c|lll|}
\hline THERMAL ENERGY DELIVERY & Identifier: & FOR-415 & \\
SYSTEM & Revision: & 1 & \\
& Effective Date: & $08 / 30 / 18$ & Page: 18 of 30 \\
\hline
\end{tabular}

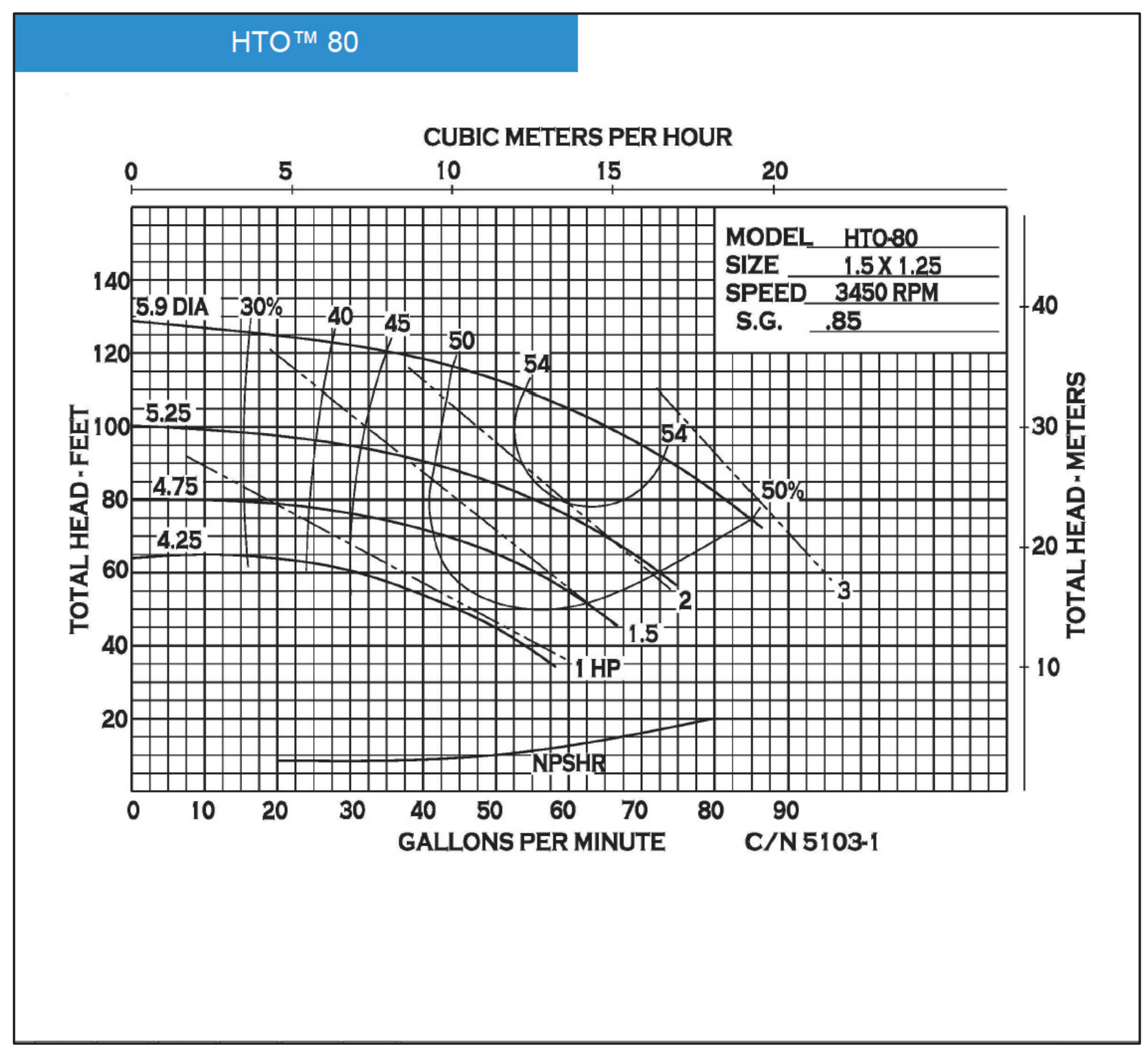




\begin{tabular}{|l|lll|}
\hline THERMAL ENERGY DELIVERY & Identifier: & FOR-415 & \\
SYSTEM & Revision: & 1 & \\
& Effective Date: & $08 / 30 / 18$ & Page: 19 of $\mathbf{3 0}$ \\
\hline
\end{tabular}

\section{НТО тм 80}

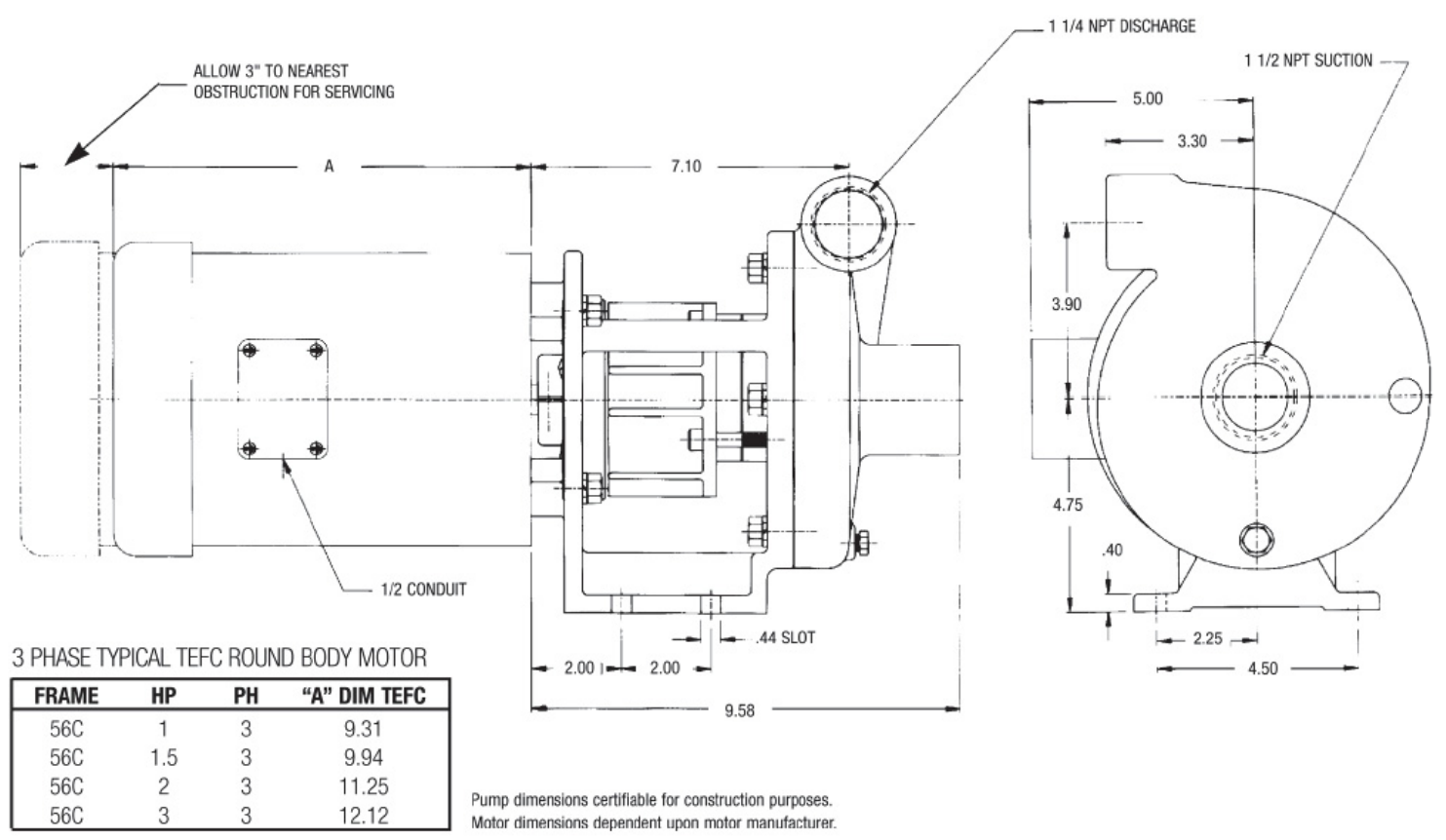




\begin{tabular}{l|lll|} 
THERMAL ENERGY DELIVERY & Identifier: & FOR-415 & \\
SYSTEM & Revision: & 1 & \\
& Effective Date: & $08 / 30 / 18$ & Page: 20 of $\mathbf{3 0}$ \\
\hline
\end{tabular}

\section{НТО тм 80}

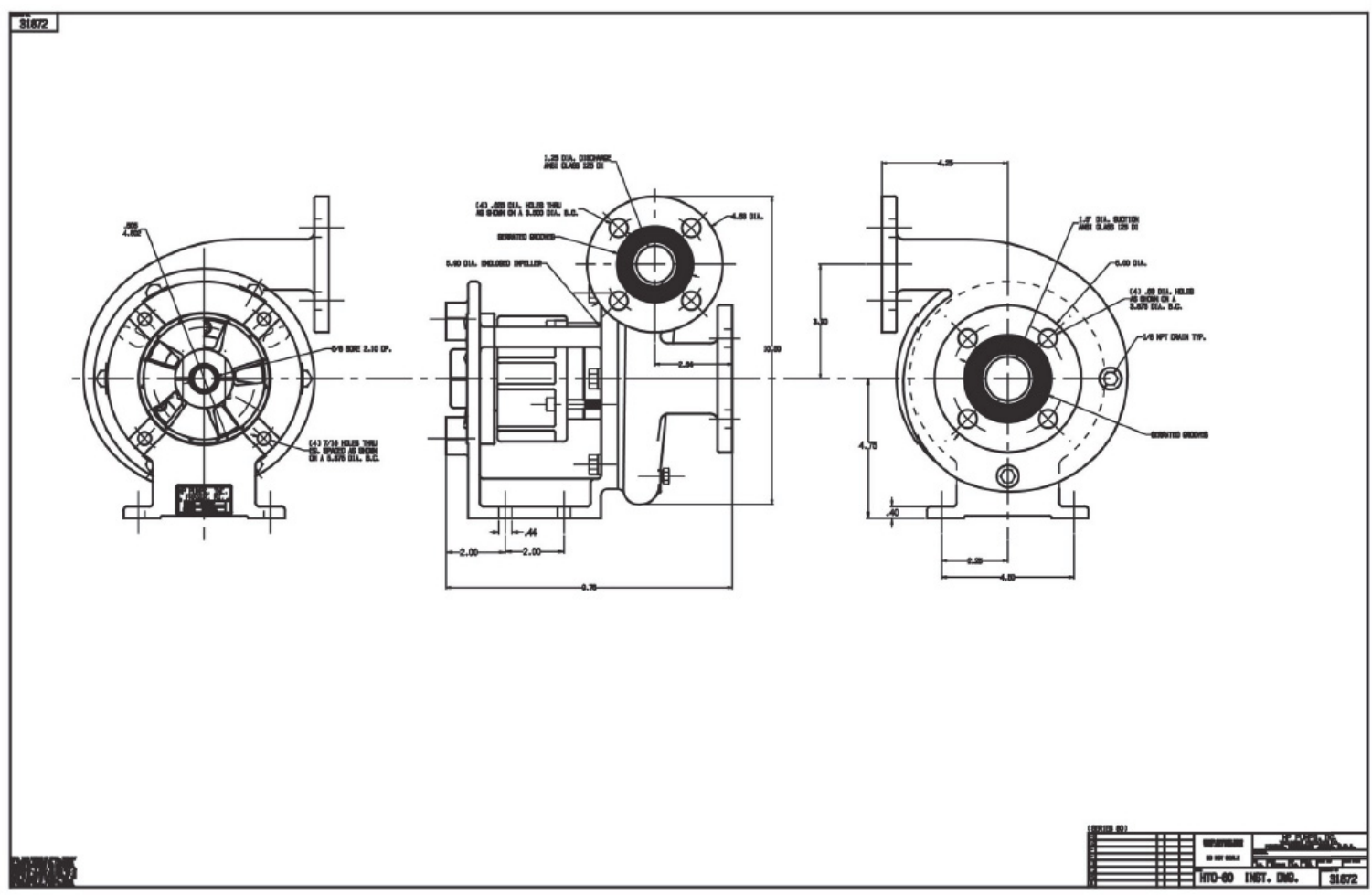

Appendix A 
Idaho National Laboratory

\begin{tabular}{|l|lll|}
\hline $\begin{array}{l}\text { THERMAL ENERGY DELIVERY } \\
\text { SYSTEM }\end{array}$ & Identifier: & FOR-415 & \\
& Revision: & 1 & \\
& Effective Date: & $08 / 30 / 18$ & Page: 21 of $\mathbf{3 0}$ \\
\hline
\end{tabular}

\section{НТО тм 80}

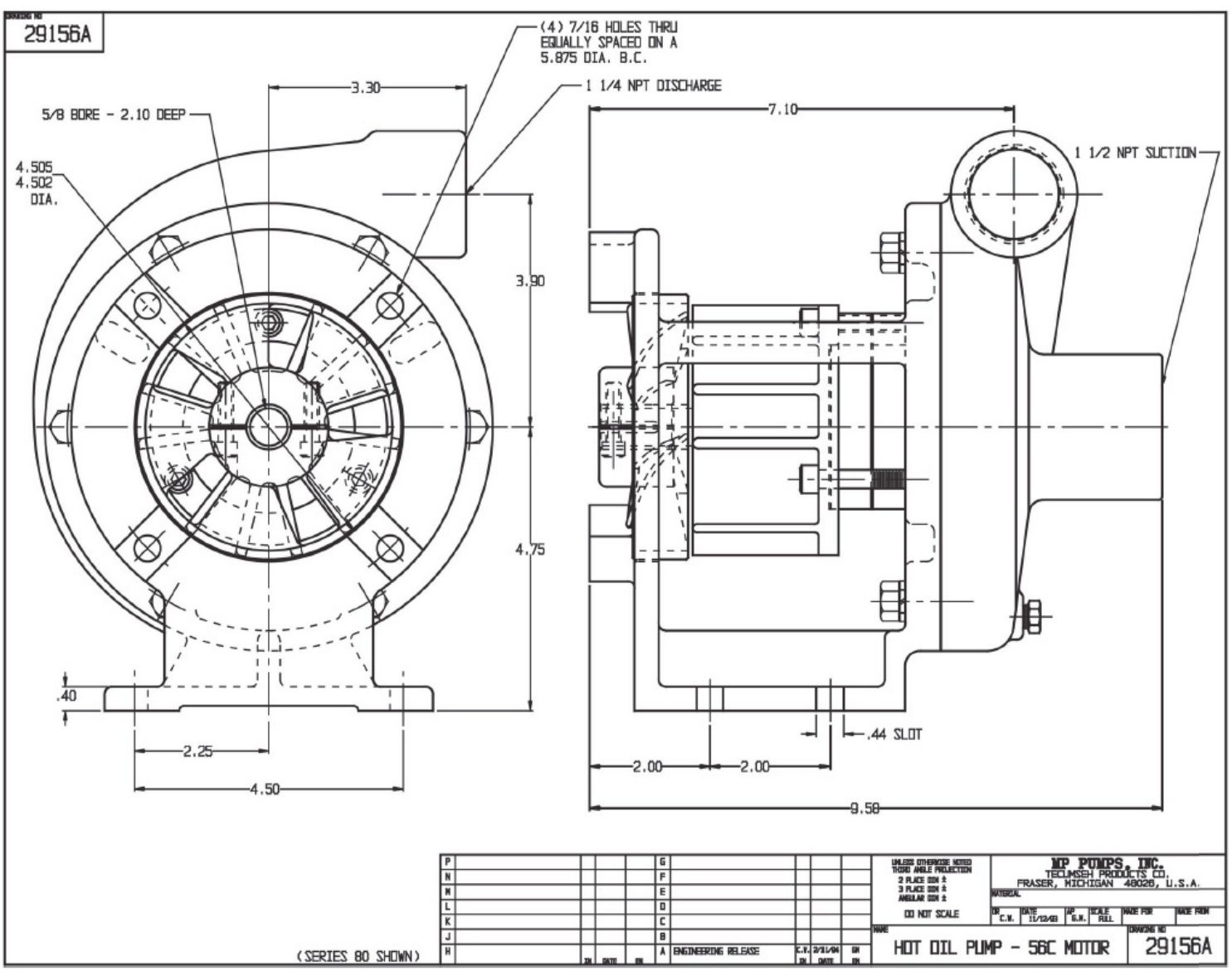

Appendix A 


\section{THERMAL ENERGY DELIVERY SYSTEM}

Identifier: $\quad$ FOR-415

Revision: $\quad 1$

Effective Date: $08 / 30 / 18$

\section{НТО тм 80}

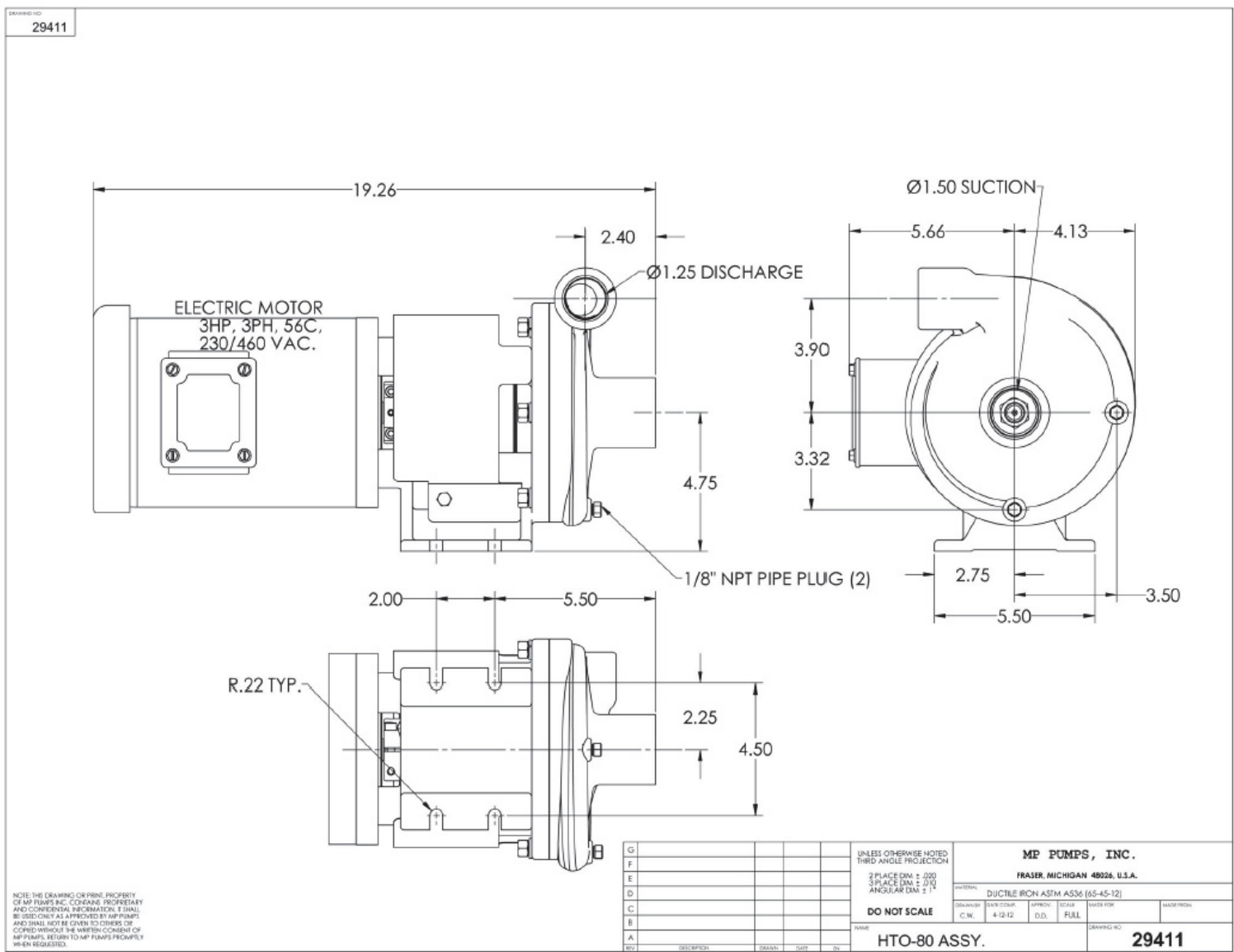




\begin{tabular}{|l|lll|} 
THERMAL ENERGY DELIVERY & Identifier: & FOR-415 & \\
SYSTEM & Revision: & 1 & \\
& Effective Date: & $08 / 30 / 18$ & Page: 23 of $\mathbf{3 0}$ \\
\hline
\end{tabular}

\section{НТО тм 80}

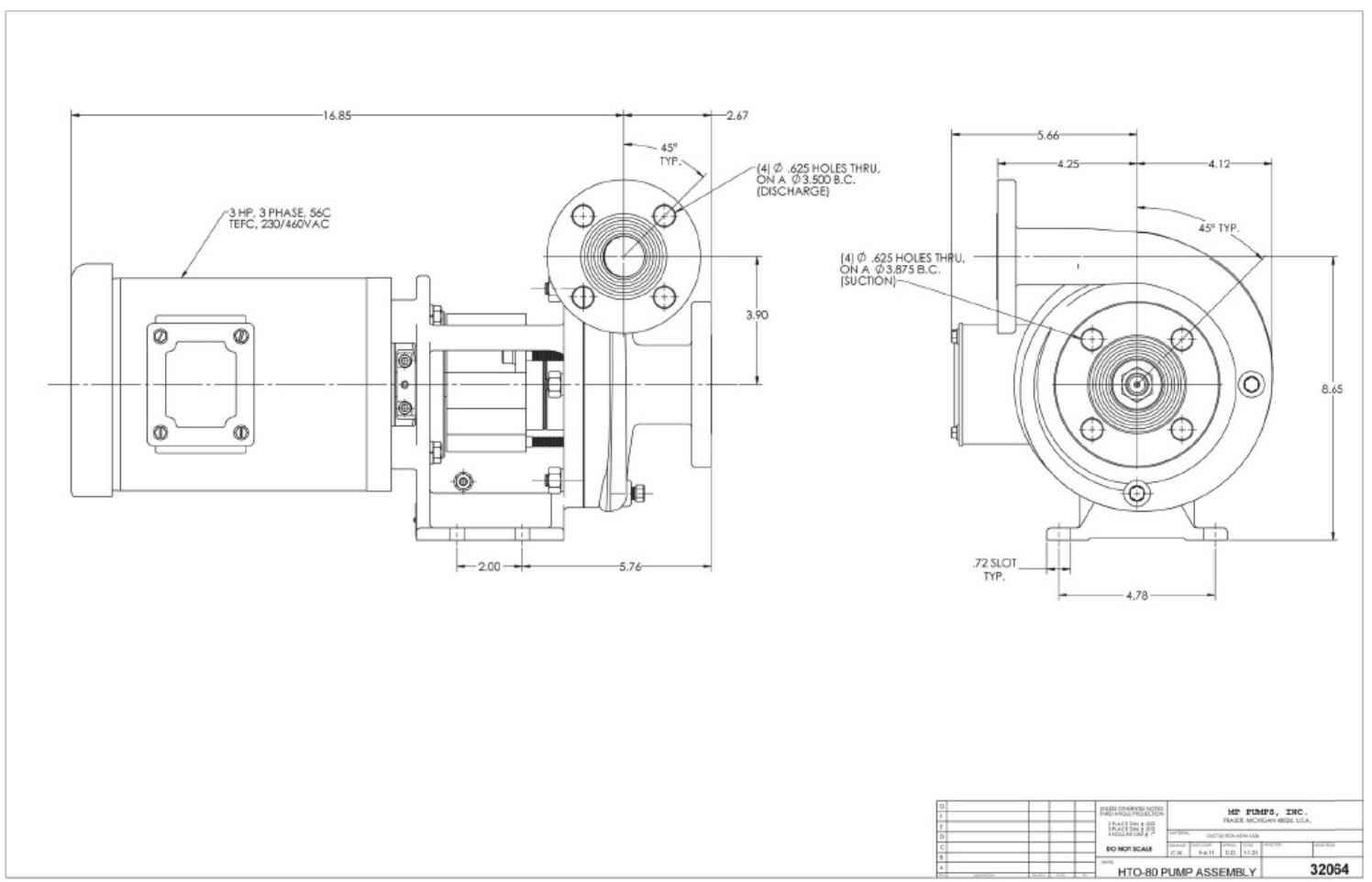




\section{THERMAL ENERGY DELIVERY} SYSTEM

Identifier:

Revision:

Effective Date: 08/30/18

\section{НТО тм 80}

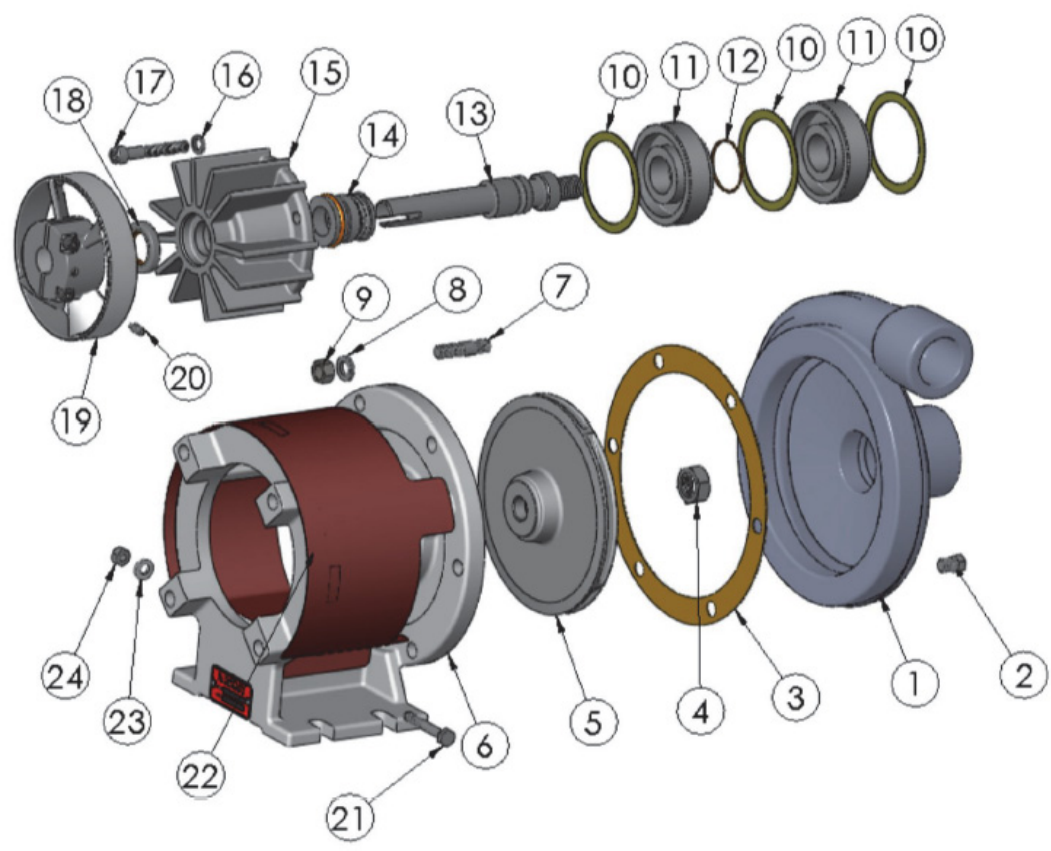

\begin{tabular}{|c|c|l|c|}
\hline ITEM & PART NO. & \multicolumn{1}{|c|}{ DESCRIPTION } & QTY. \\
\hline 1 & 25666 & HOUSING- DUCTILE IRON & 1 \\
2 & 21585 & PIPE PLUG- 1/8 NPT ZPS & 2 \\
$* 3$ & 31518 & GASKET- HOUSING & 1 \\
4 & 22655 & HEX JAM NUT ZPS - 5/8-18 & 1 \\
5 & 25910 & IMPELLER 5.90 DIA- STL. & 1 \\
6 & 29160 & ADAPTOR- DUCTILE IRON & 1 \\
7 & 21261 & STUD SS: 3/8-16 X 1.63" & 6 \\
8 & 21266 & LOCKWASHER SS- 3/8" & 6 \\
9 & 21268 & HEXNUT SS: 3/8-16 & 6 \\
$* 10$ & 29165 & GASKET- ISOLATOR & 3 \\
$* 11$ & 29158 & ISOLATOR & 2 \\
$* 11$ & 29230 & O-RING - VITON & 1
\end{tabular}

\begin{tabular}{c|cll|}
\hline ITEM & PART NO. & \multicolumn{1}{c|}{ DESCRIPTION } & QTY. \\
\hline 13 & 29166 & DRIVE SLEEVE S.S. - 56C & 1 \\
$* 14$ & 29168 & SEAL ASSY - 3/4 T-21 CAR/SIC & 1 \\
15 & 29162 & SEAL HOUSING D - HTO80 & 1 \\
16 & 29765 & WASHER FLAT STL & 3 \\
17 & 29178 & CAPSCREW STL: 5/16-18 X 2" & 3 \\
$* 18$ & 29167 & LIP SEAL- VITON & 1 \\
19 & 29164 & FAN CLAMP- DUCTILE IRON & 1 \\
20 & 33417 & SET SCREW STL: 1/4-28 & 1 \\
21 & 33810 & CAPSCREW ZPS - 5/16-18 X 1.75 & 1 \\
22 & 33273 & SHIELD ZPS - HTO80 \& 120 & 1 \\
23 & 27261 & WASHER STL - 7.2MM & 1 \\
24 & 21241 & HEXNUT S.S. - 1/4-20 & 1
\end{tabular}




\section{THERMAL ENERGY DELIVERY SYSTEM}

Identifier:

Revision:

Effective Date: $08 / 30 / 18$

\section{HTO ${ }^{\text {TM }} 80$}

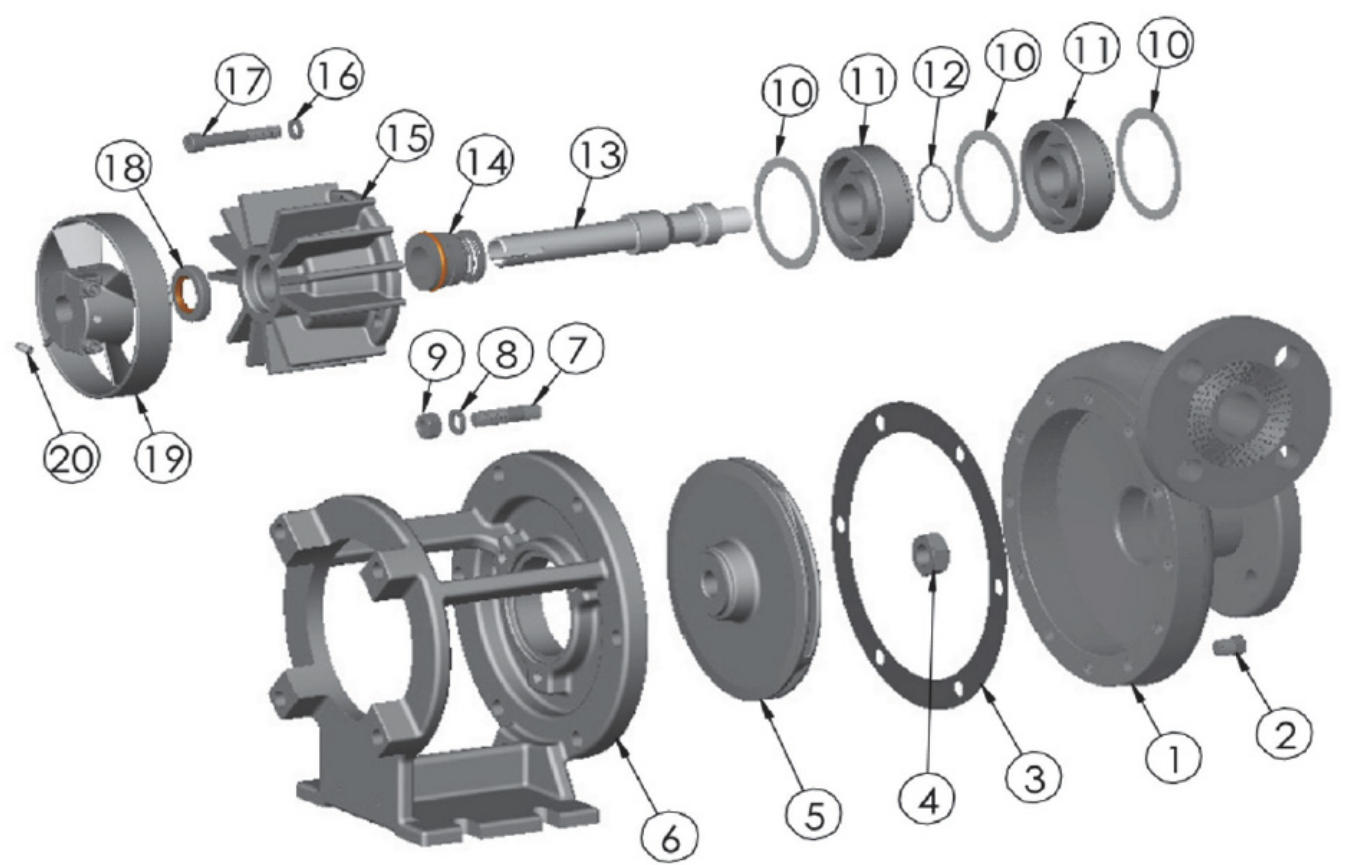

\begin{tabular}{c|c|c|c|}
\hline ITEM & PART NO. & DESCRIPTION & QTY. \\
\hline 1 & 31871 & HOUSING- DUCTILE IRON & 1 \\
2 & 21585 & PIPE PLUG- 1/8 NPT ZPS & 2 \\
3 & 31518 & GASKET- HOUSING & 1 \\
4 & 22655 & HEX JAM NUT: 5/8-18 & 1 \\
5 & 25910 & IMPELLER 5.90 DIA. DUCTILE IRON & 1 \\
6 & 29160 & ADAPTOR- DUCTILE IRON & 1 \\
7 & 21261 & STUD SS: 3/8-16 X 1.63" & 6 \\
8 & 21266 & LOCKWASHER SS- 3/8* & 6 \\
9 & 21268 & HEXNUT SS: 3/8-16 & 6 \\
10 & 29165 & GASKET- ISOLATQR & 3
\end{tabular}

\begin{tabular}{c|c|c|c|}
\hline ITEM & PART NO. & DESCRIPTION & OTY. \\
\hline 11 & 29158 & ISOLATOR & 2 \\
12 & 29230 & O-RING: VITON & 1 \\
13 & 29166 & DRIVE SLEEVE: $56 C$ & 1 \\
14 & 29168 & SEAL ASSEMBLY & 1 \\
15 & 29162 & SEAL HOUSING. DUCTILE IRON & 1 \\
16 & 29765 & WASHER STL & 3 \\
17 & 29178 & CAPSCREW STL: 5/16-18 & 3 \\
18 & 29167 & LIP SEAL- VITON & 1 \\
19 & 29164 & FAN CLAMP. DUCTILE IRON & 1 \\
20 & 33417 & SET SCREW STL: 1/4-28 & 1 \\
\end{tabular}




\begin{tabular}{|c|lll|}
\hline THERMAL ENERGY DELIVERY & Identifier: & FOR-415 & \\
SYSTEM & Revision: & 1 & \\
& Effective Date: & $08 / 30 / 18$ & Page: 26 of 30 \\
\hline
\end{tabular}

\section{Potential Thermocline Tank Dimensions}

Table 3: Potential Thermocline Tank Heights

\begin{tabular}{|c|c|c|c|c|c|}
\hline \multicolumn{7}{|c|}{ Thermocline Tank Dimensions } \\
\hline NPS [in] & \multicolumn{5}{|c|}{ Schedule } \\
\hline 36 & 10 & STD & 20 & 30 & 40 \\
\hline $\mathrm{D}_{\mathrm{o}}[\mathrm{in}]$ & 36 & 36 & 36 & 36 & 36 \\
\hline $\mathrm{t}[\mathrm{in}]$ & 0.312 & 0.375 & 0.50 & 0.625 & 0.75 \\
\hline $\mathrm{D}_{\mathrm{i}}[\mathrm{in}]$ & 35.38 & 35.25 & 35.00 & 34.75 & 34.50 \\
\hline Area $\left[\mathrm{in}^{2}\right]$ & 982.90 & 975.91 & 962.11 & 948.42 & 934.82 \\
\hline Total Height [in] & 16.61 & 16.73 & 16.97 & 17.21 & 17.46 \\
\hline Distribution Plate Distance $[\mathrm{in}]^{-166.08}$ & $\mathbf{1 6 7 . 2 7}$ & $\mathbf{1 6 9 . 6 7}$ & $\mathbf{1 7 2 . 1 2}$ & $\mathbf{1 7 4 . 6 2}$ \\
\hline
\end{tabular}

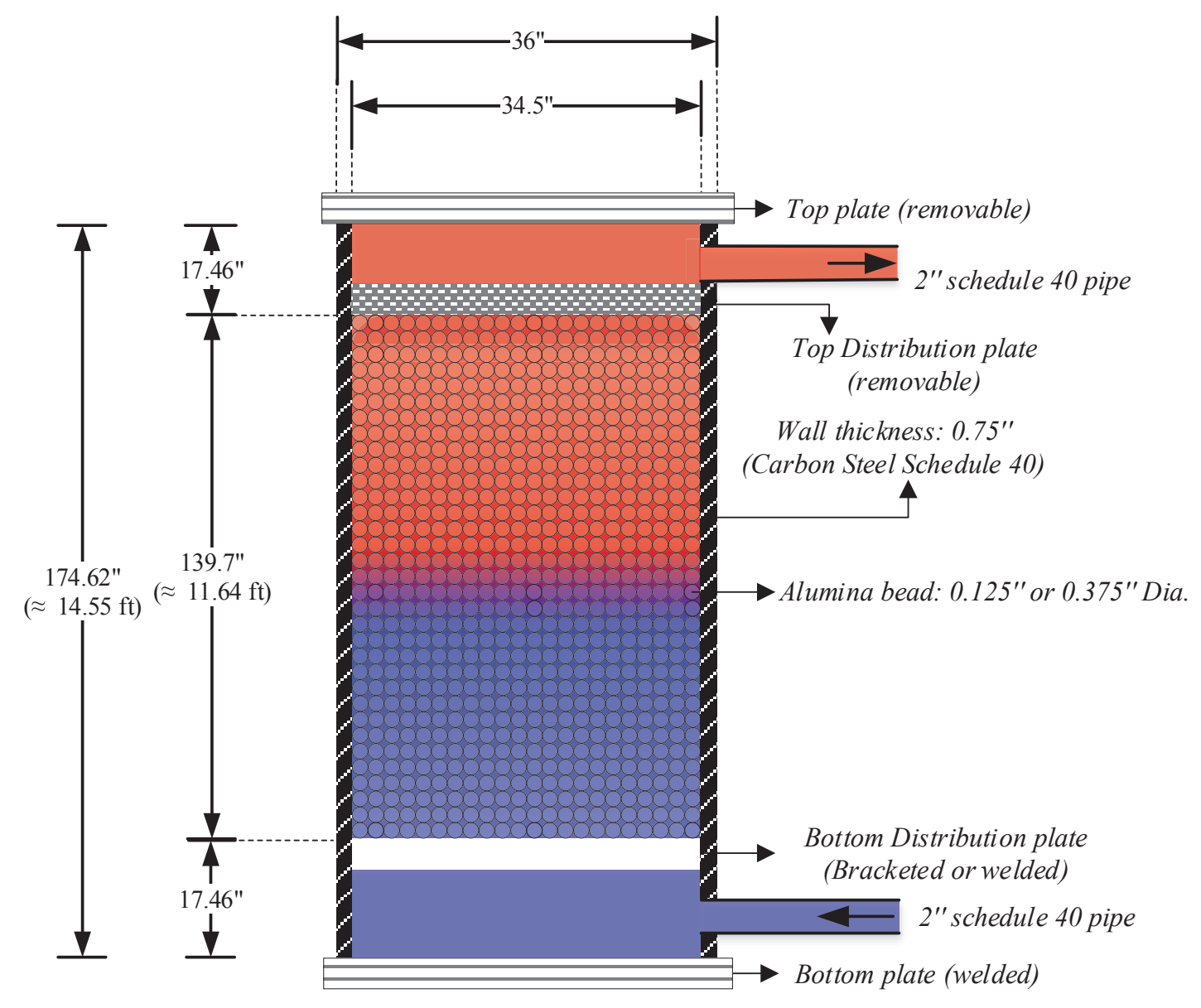

Figure 5: Potential Thermocline Tank Dimensions 
THERMAL ENERGY DELIVERY SYSTEM
Identifier:

Revision: $\quad 1$

Effective Date: 08/30/18

\section{Potential Storage Tank Dimensions}

Table 4: Potential Storage Tanks Heights

\begin{tabular}{|c|c|c|c|c|c|}
\hline \multicolumn{7}{|c|}{ Storage Tank Dimension } \\
\hline NPS [in] & \multicolumn{7}{|c|}{ Schedule } \\
\hline 36 & 10 & STD & 20 & 30 & 40 \\
\hline $\mathrm{D}_{\mathrm{o}}[\mathrm{in}]$ & 36 & 36 & 36 & 36 & 36 \\
\hline $\mathrm{t}[\mathrm{in}]$ & 0.312 & 0.375 & 0.500 & 0.625 & 0.750 \\
\hline $\mathrm{D}_{\mathrm{i}}[\mathrm{in}]$ & 35.38 & 35.25 & 35.00 & 34.75 & 34.50 \\
\hline Area $\left[\mathrm{in}^{2}\right]$ & 982.90 & 975.91 & 962.11 & 948.42 & 934.82 \\
\hline Tank Vol [gal] & & & 500 & \\
\hline Volume $\left[\mathrm{m}^{3}\right]$ & \multicolumn{1}{|l|}{1.89} \\
\hline Height $[\mathrm{in}]$ & $\mathbf{1 1 7 . 5 1}$ & $\mathbf{1 1 8 . 3 5}$ & $\mathbf{1 2 0 . 0 5}$ & $\mathbf{1 2 1 . 7 8}$ & $\mathbf{1 2 3 . 5 5}$ \\
\hline
\end{tabular}

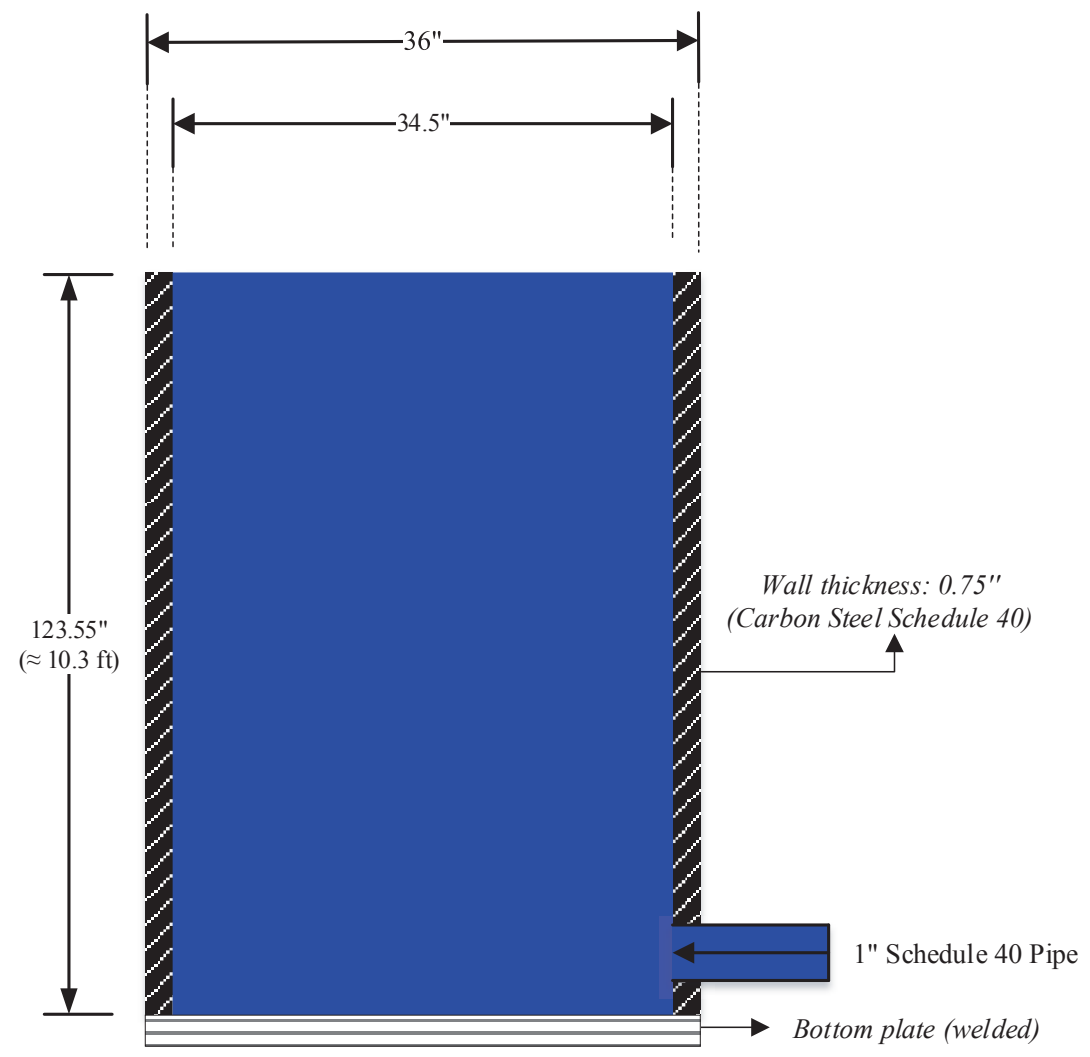

Figure 6: Potential Storage Tanks Dimensions 
THERMAL ENERGY DELIVERY SYSTEM

$\begin{array}{ll}\text { Identifier: } & \text { FOR-415 } \\ \text { Revision: } & 1 \\ \text { Effective Date: } & 08 / 30 / 18\end{array}$

\section{Potential Filtration System}

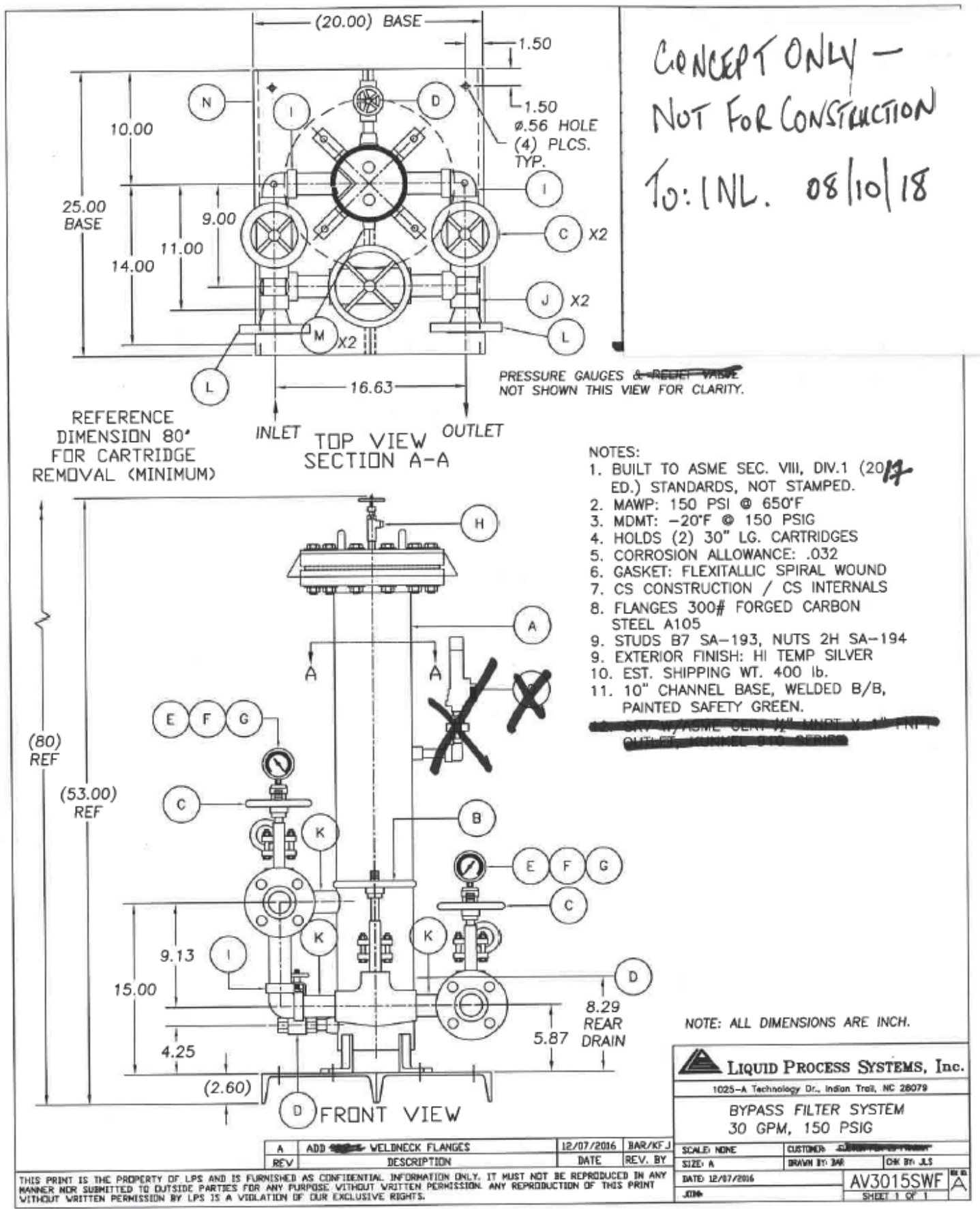

Appendix A 

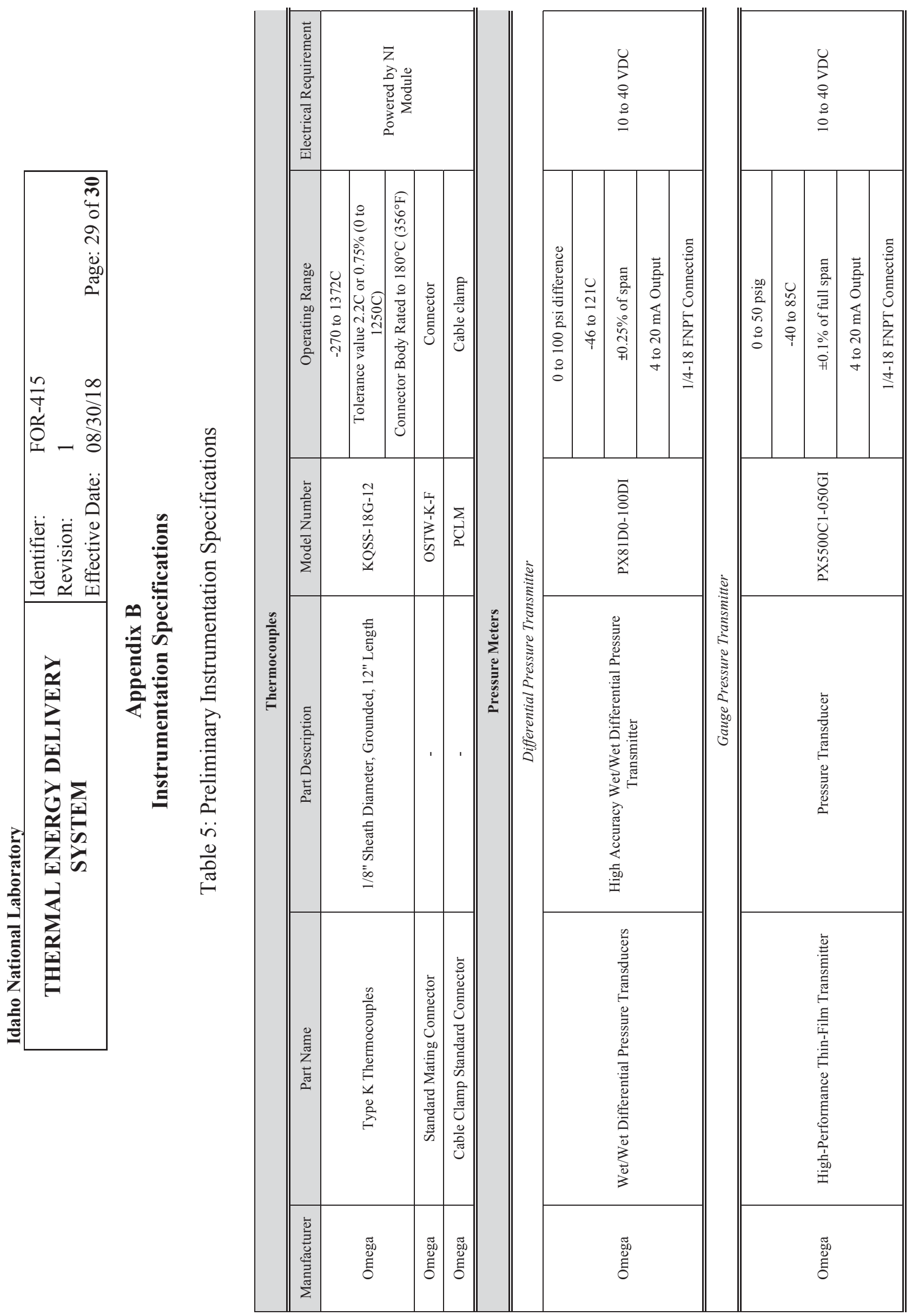


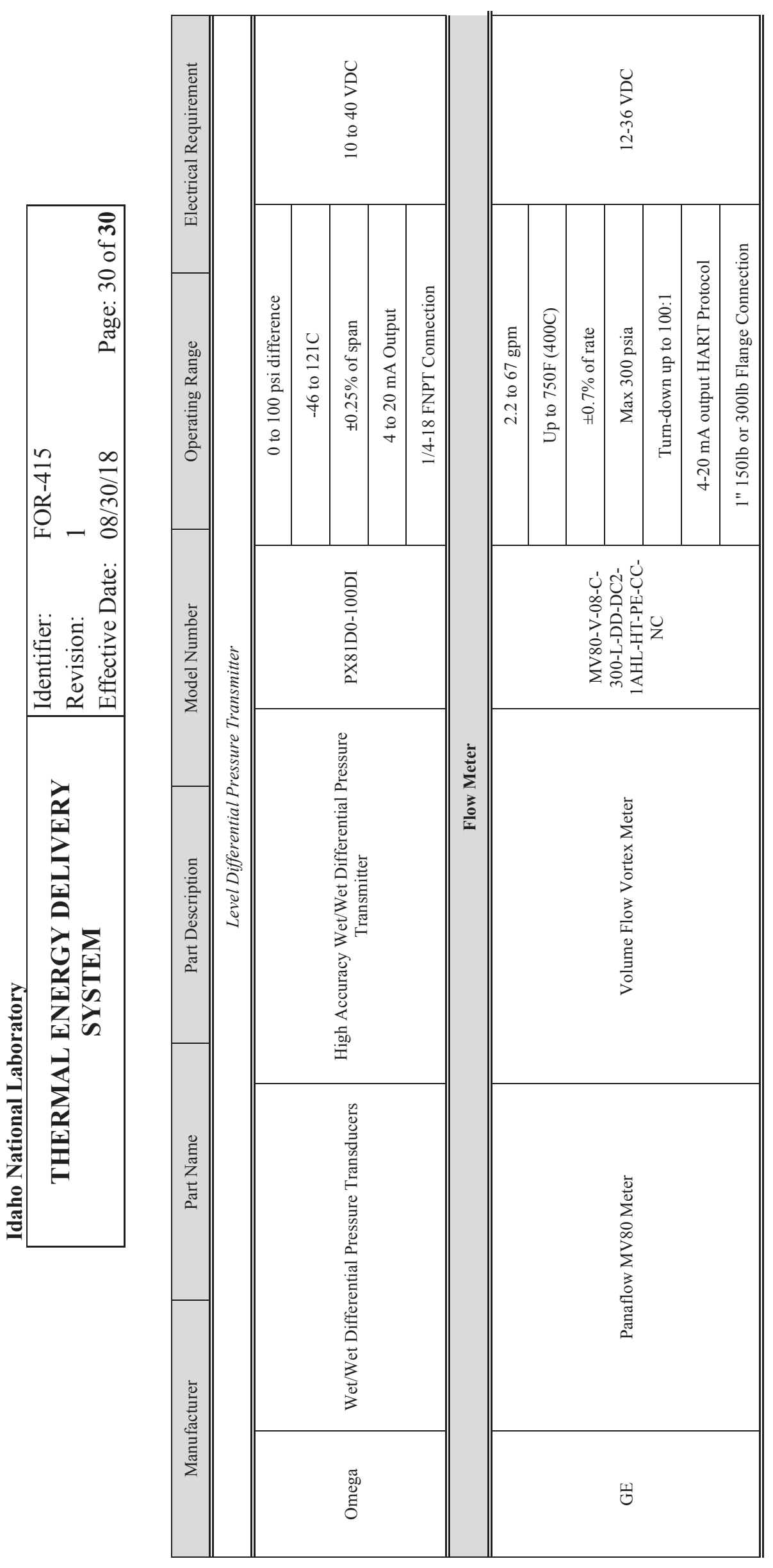

$n$
.0
$\frac{0}{0}$
$\frac{2}{2}$
$\frac{2}{4}$ 